\title{
A global compilation of U-series-dated fossil coral sea-level indicators for the Last Interglacial period (Marine Isotope Stage 5e)
}

\author{
Peter M. Chutcharavan ${ }^{1,2}$ and Andrea Dutton ${ }^{1}$ \\ ${ }^{1}$ Department of Geoscience, University of Wisconsin - Madison, Madison, Wisconsin 53706, USA \\ ${ }^{2}$ Department of Geological Sciences, University of Florida, Gainesville, Florida 32611, USA \\ Correspondence: Peter M. Chutcharavan (chutcharavan@wisc.edu)
}

Received: 10 December 2020 - Discussion started: 14 December 2020

Revised: 17 May 2021 - Accepted: 25 May 2021 - Published: 2 July 2021

\begin{abstract}
This dataset is a comprehensive, global compilation of published uranium-thorium (U-series) dated fossil coral records from $\sim 150000-110000$ years ago, as well as associated elevation measurements and sample metadata. In total, 1312 U-series measurements from 994 unique coral colonies are included in the current version of the dataset, all of which have been normalized and recalculated using the same decay constant values. Of these measurements, 444 analyses from 330 colonies are relative sea-level indicators, whereas 15 analyses from 13 colonies are marine limiting. Two example geochemical screening criteria have been included to assist users with identifying altered fossil corals that display geochemical open-system behavior, and the originally published interpretations on age quality have been preserved within the sample metadata. Additionally, a clear distinction has been made between coral colonies that are in primary growth position, which may be used for relative sea-level reconstructions, and colonies that have been transported/reworked, which cannot be used for these purposes. Future research efforts involving fossil coral sea-level reconstructions should emphasize an "integrated" and holistic approach that combines careful assessment of U-series age quality with high-precision surveying techniques and detailed facies/stratigraphic observations. This database is available at https://doi.org/10.5281/zenodo.4309796 (Chutcharavan and Dutton, 2020).
\end{abstract}

\section{Introduction and literature overview}

Uranium-thorium (U-series) dating of Last Interglacial (LIG) fossil corals has long been a key component of the paleoceanographic toolkit. Early work utilized alpha spectrometry, which has analytical uncertainties on the order of several thousand years for LIG fossil corals. Nonetheless, these early studies provided some of the first radiometric age constraints on the timing of Late Pleistocene glacial-interglacial cycles and were critical for validating the Milankovitch hypothesis (e.g., Broecker et al., 1968; Bender et al., 1979). More recently, the advent of modern mass spectrometric Useries techniques in the mid-1980s reduced analytical uncertainties of LIG fossil coral U-series ages to 1000 years (1 kyr) or less, allowing workers to precisely determine the timing of the LIG and further refine our understanding of the relationship between orbital forcing, solar insolation, and sea-level/climate change (Chen et al., 1986; Edwards et al., 1987a, b; Gallup et al., 1994; Stirling et al., 1995, 1998). In the last 3 decades, further improvements to existing thermal ionization mass spectrometry methods and the development of robust inductively coupled plasma mass spectrometry techniques have continued to push the boundaries of analytical precision, and today many labs routinely generate coral U-series ages with an analytical precision of several hundred years for the LIG (e.g., Cheng et al., 2000; Stirling et al., 2001; Andersen et al., 2008; McCulloch and Mortimer, 2008; Cheng et al., 2013).

Global synthesis studies have estimated that the LIG sealevel highstand lasted from approximately 129 to 116 thousand years ago and that global mean sea level (GMSL) was likely 6-9 m higher than at present (Kopp et al., 2009; Dut- 
ton and Lambeck, 2012; Masson-Delmotte et al., 2013; Dutton et al., 2015a). However, the rate, timing and magnitude of GMSL change within the LIG is still debated, with published interpretations ranging from a single, stable highstand peak to multiple peaks separated by ephemeral sea-level falls (Kopp et al., 2017, and references therein). Reconciling these different interpretations for how sea level evolved during the LIG is crucial for improving our understanding of ice sheet (in)stability during warm periods such as the present Holocene interglacial and for constraining the future sealevel response to human-caused climate change.

Understanding what the global fossil coral record tells us about LIG sea level requires careful interpretations of the age, elevation and underlying metadata that comprise a coral relative sea level (RSL) indicator. This is not a trivial undertaking, as data reporting protocols vary by research group and have evolved over the $30+$ years that corals have been U-series-dated using mass spectrometry $(50+$ years if alpha spectrometry is considered). It is not only important that the originally published information be collated and reported it must also be standardized. The dataset should also be easily accessible to users who do not work directly with fossil coral RSL indicators but require a ready-to-use dataset that has already been quality-checked.

Here we present, to our knowledge, the most comprehensive compilation to date of U-series-dated fossil coral RSL indicators for the LIG as a contribution to the World Atlas of Last Interglacial Shorelines (WALIS, https://warmcoasts. eu/world-atlas.html, last access: 20 April 2021). This work builds upon two previous data compilations (Dutton and Lambeck, 2012; Hibbert et al., 2016) and also includes newly compiled data from several additional studies (Al-Mikhlafi et al., 2018; Bar et al., 2018; Braithwaite et al., 2004; Dechnik et al., 2017; Kerans et al., 2019; Kindler and Meyer, 2012; Manaa et al., 2016; Muhs et al., 2014; Muhs and Simmons, 2017; Pan et al., 2018; Pedoja et al., 2018; Yehudai et al., 2017). One advantage of the approach of Dutton and Lambeck (2012) and Hibbert et al. (2016) compared to some contemporaneous compilations (e.g., Medina-Elizalde, 2013) is that these studies accounted for subtle but important systematic age offsets caused when the compiled data are not normalized to the same set of decay constants for ${ }^{234} \mathrm{U}$ and ${ }^{230} \mathrm{Th}$ and due to variations in spike calibration techniques between research groups. This work has been further built upon by Chutcharavan et al. (2018), who observed that some research groups calibrate their spike's ${ }^{230} \mathrm{Th} /{ }^{238} \mathrm{U}$ activity ratio to a standard assumed to be in secular equilibrium (e.g., HU-1), whereas the ${ }^{234} \mathrm{U} /{ }^{238} \mathrm{U}$ activity ratio was calibrated gravimetrically. These considerations are of the utmost importance for producing robust interpretations of LIG sea level, especially at the millennial scale.

A site map of all the localities included in the database is provided in Fig. 1. The dataset includes 1312 individual U-series measurements and 104 fields for a total of 136448 entries. All included U-series ages are (1) dated to between

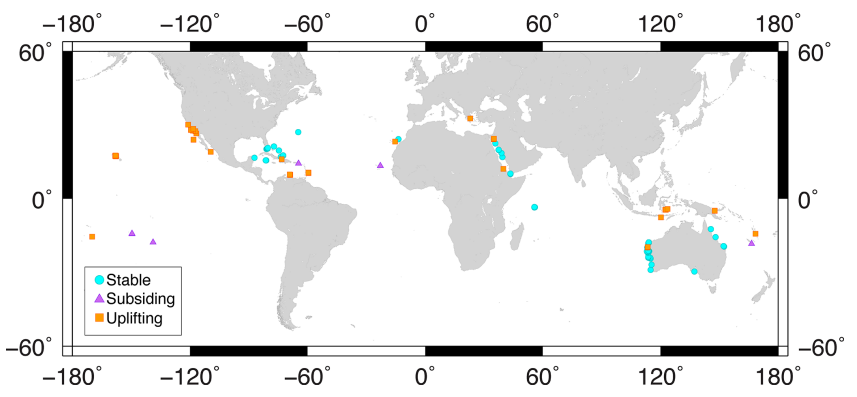

Figure 1. Site map of U-series-dated fossil corals compiled for this study. Sites are differentiated based on regional tectonic setting, with stable sites marked with a cyan circle, subsiding sites with a purple triangle and uplifting sites with an orange square. Map created using GMT v5.4.5 (Wessel et al., 2013).

150-110 kyr and/or (2) derived from a coral colony that was sampled from an LIG fossil reef unit. U-series ages and isotope ratios were recalculated using the most recent set of decay constants for ${ }^{234} \mathrm{U}$ and ${ }^{230} \mathrm{Th}$, to conform to data reporting standards that have been established by the U-series community (Cheng et al., 2013; Dutton et al., 2017). Although comprehensive, this dataset is not necessarily exhaustive, and we fully expect that the U-series component of WALIS will expand in the coming years as users continue to add legacy data and data from newly published studies.

We preserved the originally reported values and metadata within WALIS, while also producing two pre-screened, interpreted versions of the dataset based on data quality that can assist users with identifying fossil coral U-series dates that display open-system behavior. The intention is that this combined approach will ensure that this dataset will adhere to FAIR data principles, being findable; accessible; interoperable; and, above all, reusable (Wilkinson et al., 2016). This dataset is open source, and the most recent version can be found at https://doi.org/10.5281/zenodo.4309796 (Chutcharavan and Dutton, 2020).

\section{Methods}

This data compilation is one component of the WALIS project, which seeks to document all previously published geologic and chronostratigraphic constraints on RSL during the LIG. Although the primary focus of our contribution is on the U-series aspect of the fossil coral record, this information is inseparable from the elevation information and associated metadata when reconstructing RSL at fossil reef sites. A Useries-dated fossil coral can be used as an RSL indicator, provided that certain criteria are met. In a recent review, Rovere et al. (2016) proposed that an RSL indicator has three key components:

1. the indicator's position, both in terms of geographic coordinates and relative to an established height datum; 
2. the indicator's position relative to local sea level at the time it was deposited; and

3. some form of radiometric or chronostratigraphic age constraint on the timing of deposit formation.

If a coral with a U-series age has been collected in primary growth position and meets criteria 1 and 2, then the coral is considered an RSL indicator. In the absence of paleowater depth information (i.e., the sample does not meet criterion no. 2), corals are generally considered as marine limiting because most coral taxa are limited to below mean lower low water/mean low water springs (MLLW/MLWS), although certain coral taxa and growth forms can colonize the intertidal zone. Hence, in the absence of any additional paleoenvironmental context, sea level is considered to have been at or above the elevation of the top of the coral colony. Fossil coral RSL indicators, however, are most useful when the depth at which the coral was growing is known (see Sect. 2.4).

Identification of reliable fossil coral RSL indicators requires careful vetting of each sample's age (i.e., diagenetic screening) and vertical position relative to past sea level. This is important because ignoring additional relevant observations and metadata can result in erroneous conclusions about past sea-level change. In this compilation, we included new paleowater depth interpretations, as well as several screening "scenarios" that were designed to screen out altered samples using a consistent set of defined criteria. These screening scenarios are not intended to be the final word on which coral samples should be accepted/rejected in future studies. Rather, our twin objectives here are (1) to highlight best practices when interpreting fossil coral RSL data and (2) to provide curated example datasets that are immediately available to WALIS users seeking a current best estimate of interpreted RSL in space and time using the coral data. We caution that the screened datasets presented here may not identify every open-system coral, so even U-series ages that pass a particular closed-system criterion still need to be evaluated in the context of existing geologic/sedimentary evidence to assess whether the age is meaningful. In other words, this screening process is only the first step in interpreting the sea-level history based on fossil coral data. Additional stratigraphic, sedimentologic or other metadata may provide justification to modify or reject these preliminary age interpretations. Below, we explain the method we used to develop these datasets and also briefly address the effects of tectonics, glacial isostatic adjustment and dynamic topography on solid-earth displacement, which can cause substantial departures in RSL relative to GMSL.

\subsection{Database structure and major changes from previous compilations}

A simplified overview of the WALIS U-series fossil coral dataset and workflow is provided in Fig. 2, and the database field descriptors can be found here:

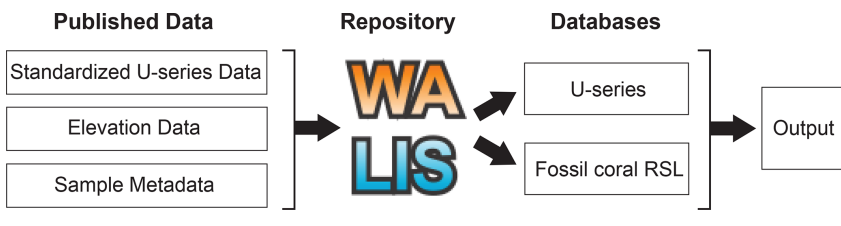

Figure 2. Simplified flowchart of WALIS coral U-series database structure. All coral age, elevation and metadata are included in the "U-series" component of the database, whereas the "fossil coral RSL" database only includes entries from corals that are in primary growth position.

https://doi.org/10.5281/zenodo.3961543 (Rovere et al., 2020). Published U-series analyses, elevation measurements and relevant metadata for each dated fossil coral are uploaded into WALIS either (1) manually via an online user interface or (2) with multiple entries at once using a spreadsheet template. Once entered into WALIS, all of the uploaded information is added to the WALIS fossil coral U-series database, and each analysis is assigned a unique identifier (WALIS U-series ID). Finally, all analyses from corals that can be used as RSL indicators (i.e., that are both in primary growth position and have an associated elevation measurement) are further subset into a fossil coral RSL database. Both databases can then be downloaded by any WALIS user.

This dataset contains several new features that have been added since the Dutton and Lambeck (2012) and Hibbert et al. (2016) compilations. Several key updates are as follows:

1. New sample identifiers are included, which make it easier to identify which U-series analyses are associated with the same coral colony. Sample IDs are reported in the format XX00-000-000. The first four digits denote the study that the coral age was published in, whereas the following sets of three numbers represent the coral sample and U-series analysis, respectively. For example, CH91-001-002 is the second U-series age reported for the first coral (here denoted with the number "001"), published in Chen et al. (1991). In situations where a coral specimen has been reanalyzed in multiple studies (e.g., for many samples from Barbados), the first four digits will refer to the oldest paper in which U-series ages were reported, while the "references" field will indicate the study the analysis came from. This ensures that the user can easily distinguish which samples came from the same coral colony, which was not always clear in earlier iterations of this database. This sample naming system has also been utilized for samples dated using other techniques that are reported in WALIS by other workers.

2. Sample elevations are now reported both in meters above mean sea level (a.m.s.l.) and relative to MLLW/MLWS. In cases where a proximal tide gauge 
datum was not available, this conversion was done using the IMCalc software package of Lorscheid and Rovere (2019).

3. All color coding from the Hibbert et al. (2016) database has been removed. This information is now stored in the "comment" columns.

4. The columns for reporting coral taxonomic information have been revamped to allow entry of family, genus and species information for each coral sample. Coral taxa were updated to reflect the most recent taxonomic classification as reported by the World Register of Marine Species (WoRMS, http://www.marinespecies.org/, last access: 25 February 2019). Reported coral taxonomic IDs are still preserved, and additional information, such as coral morphology, can be added in the comments field for this section.

5. All U-series ages from transported corals are now marked as not in primary growth position, even if the original publication explicitly states that the sample is in situ (e.g., an in situ clast/conglomerate).

6. We have back-calculated U-series activity ratios, when possible, that were not reported in the original publication and had not already been done by Hibbert et al. (2016).

7. As with Hibbert et al. (2016), all ages and activity ratios, where appropriate, have been recalculated using the Cheng et al. (2013) decay constants for ${ }^{230} \mathrm{Th}$ and ${ }^{234} \mathrm{U}$, and we have normalized reported activity ratios to account for systematic biases due to differences in interlaboratory spike calibration techniques. This was done using the open-source software EARTHTIME Redux (ET_redux; https://github.com/CIRDLES/ET_ Redux, last access: 18 August 2019). Additionally, the data normalization procedure now accounts for certain cases where the ${ }^{230} \mathrm{Th} /{ }^{238} \mathrm{U}$ activity ratio of a laboratory's spike was calibrated to a secular equilibrium standard, but the ${ }^{234} \mathrm{U} /{ }^{238} \mathrm{U}$ activity ratio was calibrated gravimetrically. This situation was first addressed for fossil coral U-series ages from $\sim 60$ to $0 \mathrm{kyr}$ (Chutcharavan et al., 2018) but had not yet been applied to the LIG fossil coral dataset.

8. We have restored some of the original information and comments from Dutton and Lambeck (2012) that were not included in the Hibbert et al. (2016) compilation.

9. Locality information for Barbados reef terraces have been standardized and reformatted in cases where there were multiple names for the same site.

\subsection{U-series diagenetic considerations}

Corals precipitate their skeletons directly from dissolved ions in seawater, forming a calcium carbonate mineral called aragonite. As part of this process, uranium (U) is incorporated at parts-per-million concentrations as impurities within the aragonite crystal lattice, and in ideal, closed-system conditions thorium (Th) concentrations are negligible. This is because of the high particle reactivity of $\mathrm{Th}$, which causes the element to have a relatively short residence time in the water column. Once the coral skeleton has formed, the U-series radiometric clock is effectively started, and the elapsed time is measured by the ingrowth of ${ }^{230} \mathrm{Th}$ from the radioactive decay of ${ }^{234} \mathrm{U}$ and ${ }^{238} \mathrm{U}$ as the system returns to secular equilibrium (Edwards et al., 1987a, 2003). It is the disequilibrium that arises from the combination of high $U$ concentrations and negligible detrital Th content that enables high-precision U-series dating of coral skeletal material, thus making fossil corals both valuable RSL indicators and an important source of absolute age control for other marine-derived sediments (e.g., marine terrace deposits).

Unfortunately, coral skeletal material is also highly susceptible to post-depositional alteration (i.e., diagenesis), particularly after exposure to meteoric waters, as is often the case with emergent LIG reef units (Thompson et al., 2003). As a result, a U-series date (i.e., calculated from U-series measurements without interpretation) must be carefully evaluated for signs of geochemical open-system behavior before it can be used to constrain a fossil coral age, which is an interpretation of the U-series date. Prior to U-series dating, coral samples are frequently prescreened using X-ray diffraction (XRD) and thin-section microscopy to identify evidence of recrystallization and/or alteration of coralline aragonite to secondary calcite minerals. Even coral samples that do not have detectable calcite and are not recrystallized can still yield anomalously young/old ages for an LIG deposit, indicating that mineralogically pristine samples can still display open-system behavior with respect to U-series isotopes (e.g., Fig. 3). Therefore, additional geochemical variables are often used to evaluate the quality of U-series ages (e.g., see Sect. 2.3).

Several models have been proposed to correct U-series ages that display open-system behavior, but it is well understood that patterns of diagenesis in altered corals at a study site follow multiple diagenetic pathways that cannot be explained by a single model (Henderson and Slowey, 2000; Scholz et al., 2007; Thompson et al., 2003; Villemant and Feuillet, 2003). While there are circumstances in which altered coral samples may be good candidates for open-system correction, this would require further analysis of diagenetic trends at each site, which is beyond the scope of this study, as no single open-system model can explain all of diagenetic variability in the dataset. For example, the Thompson et al. (2003) open-system model is well suited to correct diagenetic arrays common to Barbados and some localities in 

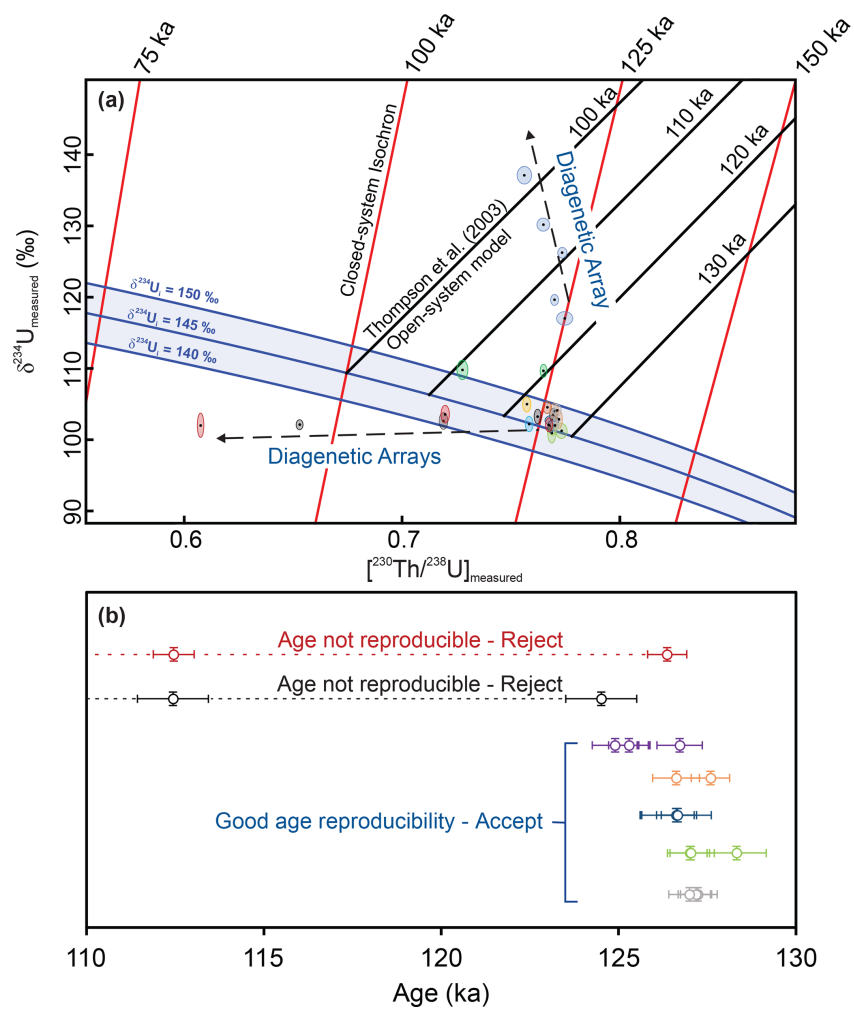

Figure 3. Examples of open-system behavior from LIG fossil coral U-series data. (a) Evolution diagram with data from the Seychelles plotted. Red lines are closed-system isochrons, while black lines are open-system isochrons based on the Thompson et al. (2003) model. Analyses that fall within the shaded blue region are treated as closed-system ages, assuming that the $\delta^{234} \mathrm{U}$ value of LIG seawater is the same as today $\left(\delta^{234} \mathrm{U}_{\text {modern }}=145 \%\right.$; Andersen et al., 2010a; Chutcharavan et al., 2018). Data points that are the same color represent different subsamples from the same coral colony. Several prominent diagenetic arrays are indicated with dashed arrows. (b) Analyses from panel (a) that passed closed-system criteria plotted by age. While the red and black measurements individually meet closed-system criteria, lack of age reproducibility between different subsamples from the same coral colony is indicative of opensystem behavior, and these ages should be rejected. Data plotted in panels (a) and (b) from Dutton et al. (2015b).

Western Australia. It does not, however, explain all modes of diagenesis present in the fossil coral record (e.g., Figs. 3a, 4). Hence, this analysis focuses on assessing closed-system ages.

\subsection{Geochemical data quality assessment}

Previous studies typically adopted a set of geochemical screening criteria to remove U-series data that have been altered through open-system behavior (e.g., Scholz and Mangini, 2007). Three of the most common geochemical variables used are

1. calcite content;

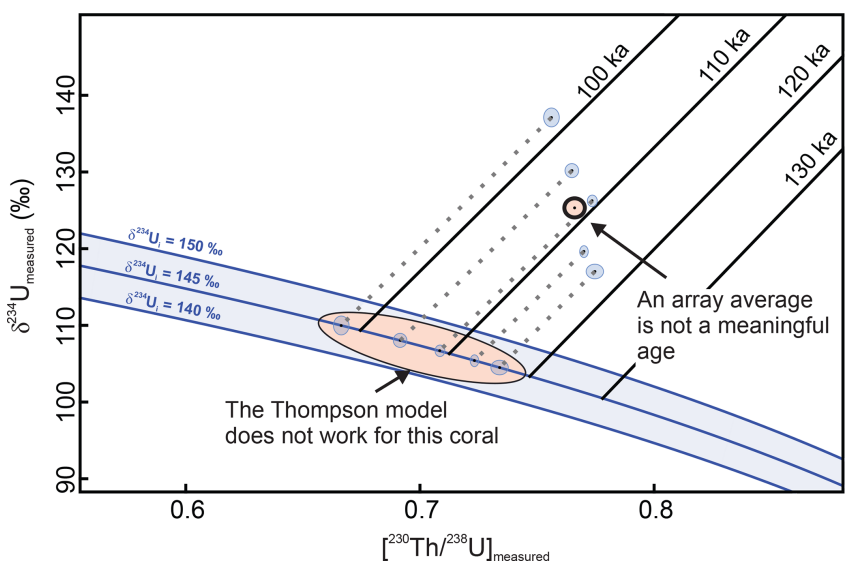

Figure 4. Open-system model of Thompson et al. (2003) applied to U-series measurements from Seychelles sample DU15-010 from Fig. 3a (Dutton et al., 2015b). In this case, the diagenetic array is roughly perpendicular to the open-system isochrons, so the opensystem correction does not change the high degree of age variability within this coral colony ( $\sim 20 \mathrm{kyr}$ in total). For this same reason, an array average does not yield a meaningful age.

2. detrital ${ }^{232} \mathrm{Th}$ concentrations, where high ${ }^{232} \mathrm{Th}$ content can result in anomalously old ages; and

3. $\delta^{234} \mathrm{U}_{\mathrm{i}}$, which, in a closed-system coral, should represent the uranium isotopic composition of ambient seawater at the time of coral growth.

For each published data source, the original list of ages that were accepted/rejected by the study authors is recorded in WALIS. It is often difficult to directly compare screened data between different publications and research groups, as the specific screening criteria applied can vary substantially from study to study. As a result, previous global fossil coral compilations (Dutton and Lambeck, 2012; Hibbert et al., 2016) have applied these screening criteria uniformly across the entire dataset to ensure that only the most geochemically pristine samples were used for sea-level interpretations. Applying a blanket screening criterion, however, results in the vast majority of U-series analyses being rejected and ignores differences that may exist in the nature of diagenesis at different sites and with different coral taxa. Therefore, we applied two sets of screening protocols to the dataset: (1) a "strict" protocol that applies uniform screening cutoffs to each U-series age based on the three geochemical variables listed above and (2) a "flexible" protocol that allows for site- and samplespecific criteria, particularly where multiple subsamples of the same coral have been dated.

The strict screening protocol follows the general approach of Dutton and Lambeck (2012) and Hibbert et al. (2016), with some modification in the case where multiple subsamples from a single coral specimen were dated. To be accepted, a sample must have

1. calcite content $<2 \%$, 
2. detrital ${ }^{232} \mathrm{Th}$ concentration $<2$ parts per billion ( $\mathrm{ppb}$ ), and

3. $\delta^{234} \mathrm{U}_{\mathrm{i}}$ within $5 \%$ of the average value for modern corals/seawater $(\sim 145 \%$; Andersen et al., 2010a; Chutcharavan et al., 2018).

If any of these values are not reported or cannot be calculated, the U-series age is rejected. Additionally, in the case where multiple subsamples of the same coral pass the strict screening criteria, the ages must also be reproducible (i.e., overlap or nearly overlap within analytical uncertainty) and not lie along a diagenetic array (e.g., Fig. 3). Although this last stipulation regarding age reproducibility is necessary to evaluate corals with multiple dated subsamples properly, it has the consequence of biasing the dataset towards corals that have only been dated once but pass the screening criteria. Ideally, we would only use fossil coral ages that have been reproduced by multiple subsamples as RSL indicators, to ensure that multiple subsamples from the same coral specimen yield reproducible ages. However, this was not feasible for the dataset considered here, as it would have required rejection of nearly all the coral data that were compiled. Although the application of uniform screening criteria to the global dataset is appealing from a logistical perspective and gives the appearance that data are being treated equally, there can be important methodological differences and additional contextual information that cannot be incorporated using a uniform screening protocol. To address this, we also applied a flexible screening protocol that evaluates each study and study site independently, so that nuances in U-series age interpretations could be evaluated.

Many screening decisions are context based and were addressed separately for each site, but some general modifications to the strict screening protocol are addressed here. First, we expanded the calcite screening threshold to include all corals that are below the limit of quantification for the XRD method employed, which can be as high as 4 or $5 \%$ for some studies.

Second, we allowed for a higher ${ }^{232} \mathrm{Th}$ threshold of $12 \mathrm{ppb}$ (i.e., a ${ }^{230} \mathrm{Th} /{ }^{232} \mathrm{Th}$ activity ratio of $\sim 500$ ) when age reproducibility can be verified by multiple subsamples from the same coral. This roughly corresponds to a $1 \%$ or $\sim 0.13 \mathrm{kyr}$ ) effect on the measured U-series age, assuming a bulk upper-continental-crust contaminant (Dutton et al., 2015; Taylor and McLennan, 1995; Wedepohl, 1995). Although it has been demonstrated that the composition of detrital thorium contamination can depart from bulk crustal values at different study sites (Cobb et al., 2003; Shen et al., 2008), our approach nonetheless offers a first-order estimate that should approximate the degree of contamination. Additionally, we accepted samples that do not have detrital Th information reported in cases where rejecting these samples would have effectively removed the study site from the dataset. Cases where this has been done are noted explicitly in the site summaries.
Finally, we expanded the upper limit of the $\delta^{234} \mathrm{U}_{\mathrm{i}}$ threshold by $2 \%$, so that the new range of acceptable $\delta^{234} \mathrm{U}_{\mathrm{i}}$ values is $140 \%$ o- $152 \%$, provided that the newly accepted ages are stratigraphically consistent with the other ages from the site. This was done, in part, because the average $\delta^{234} \mathrm{U}_{\mathrm{sw}}$ value for the LIG is not constrained and there is evidence that the uranium isotopic composition of seawater has varied by several per mil on glacial-interglacial timescales (Chen et al., 2016; Chutcharavan et al., 2018). More importantly, it is also clear that there are likely subtle, unresolved biases in interlaboratory calibration protocols that could result in systematic offsets of a few per mil, depending on the lab where a sample was dated (Chutcharavan et al., 2018, and references therein).

The purpose of these screening protocols is, specifically, to identify the highest-quality closed-system fossil coral Useries ages that can be used to provide constraints on sealevel change within the LIG (i.e., on suborbital/millennial timescales). We acknowledged that some users may only be interested in knowing whether a geologic feature is broadly constrained to the LIG by the fossil coral U-series data, and we have endeavored to make such distinctions where applicable in the site descriptions (see Sect. 3). Users are also cautioned that the screening protocols provided in this paper are only intended as guidelines to assist users with identifying coral U-series ages that display closed-system behavior. A Useries measurement fitting a set of predetermined geochemical parameters does not automatically imply that an age is robust or that it can provide meaningful radiometric age constraints on LIG sea-level change. Therefore, it is important for the user to carefully evaluate whether a screened age is consistent with the available geologic context. Additionally, the two example screening protocols provided here are by no means the only way to screen fossil coral U-series data, and we have included a functionality within the WALIS U-series database to upload alternative screening interpretations.

\subsection{Growth position and paleowater depth uncertainties}

\subsubsection{Identifying growth position corals}

Even if a fossil coral is associated with a robust U-series age, it cannot be treated as an RSL indicator if the vertical position of the sample relative to paleo-sea-level is not known. This cannot be determined if a coral has been reworked as a cobble or clast since it is not known where the sample originally grew. Therefore, only a fossil coral that has not been transported (i.e., is in primary growth position) can be considered an RSL indicator.

Determining whether a coral sample is in growth position from legacy data can be challenging. The reporting criteria used are not standardized across the literature, and even the terminology used can vary from paper to paper, if it is addressed at all. Generally speaking, the two most common expressions used to indicate that a coral is in place are "growth 
position" and "in situ". Growth position is usually interpreted as expressing greater confidence than in situ, as it implies that the coral is in the correct growth orientation or that a clear basal attachment to the reef substrate is visible at the outcrop scale. For the present study, however, we accepted corals with either designation as an RSL indicator. Hereafter, corals that are listed as either in situ or growth position will be colloquially referred to as in "primary growth position".

There are two unique circumstances for which additional information is required to determine if a coral is in primary growth position. First, some studies refer to a coral specimen as being in primary growth position, yet the depositional context given clearly indicates that the coral has been reworked (e.g., "in situ clast" or "in situ conglomerate"). We interpreted such samples as not being in primary growth position. Second, we accepted the designation of "coral framework" as equivalent to in situ, and therefore primary growth position, for samples that were collected via drill core (e.g., Camoin et al., 2001; Thomas et al., 2009; Vezina et al., 1999), because in these cases it was impossible to explore the sample's relationship to the rest of the reef unit. It is important, however, to recognize that it is possible for coral colonies to have been transported but still appear to be in primary growth position. For example, there are three samples from Stein et al. (1993) collected in Papua New Guinea (sample IDs ST93003, ST93-004 and ST93-014) that are reported as being in growth position but are ultimately derived from detached limestone blocks and, therefore, were not treated as primarygrowth-position corals. In some cases, this additional context is not provided in the published literature, and reappraising the existing stratigraphic evidence at certain field cites may be warranted (e.g., Skrivanek et al., 2018). However, such an a posteriori assessment is outside the scope of this study and the WALIS special issue.

\subsubsection{Constraining paleowater depth uncertainties}

After determining that a coral sample has a reliable U-series age and is in primary growth position, the final challenge involves determining the paleowater depth uncertainty for the coral. As a primary-growth-position coral, we know that the sample is, at minimum, marine limiting, as corals from the highest growth position at an LIG fossil reef site did not necessarily grow directly beneath the paleo-sea-surface. Many of the studies included in our compilation rely on modern analogue studies of present-day reef ecology to constrain paleowater depth uncertainties.

There are two primary techniques that use the modern analogue approach to constrain paleowater depth (Fig. 5). The first technique is an assemblage-based approach, which examines a series of variables such as coral taxa/growth forms present, associated coralline algal species and relevant sedimentary context to identify the most probable depth range for the reef unit in which the coral grew (Abbey et al., 2011; Cabioch et al., 1999; Dechnik et al., 2017; Lighty et al.,

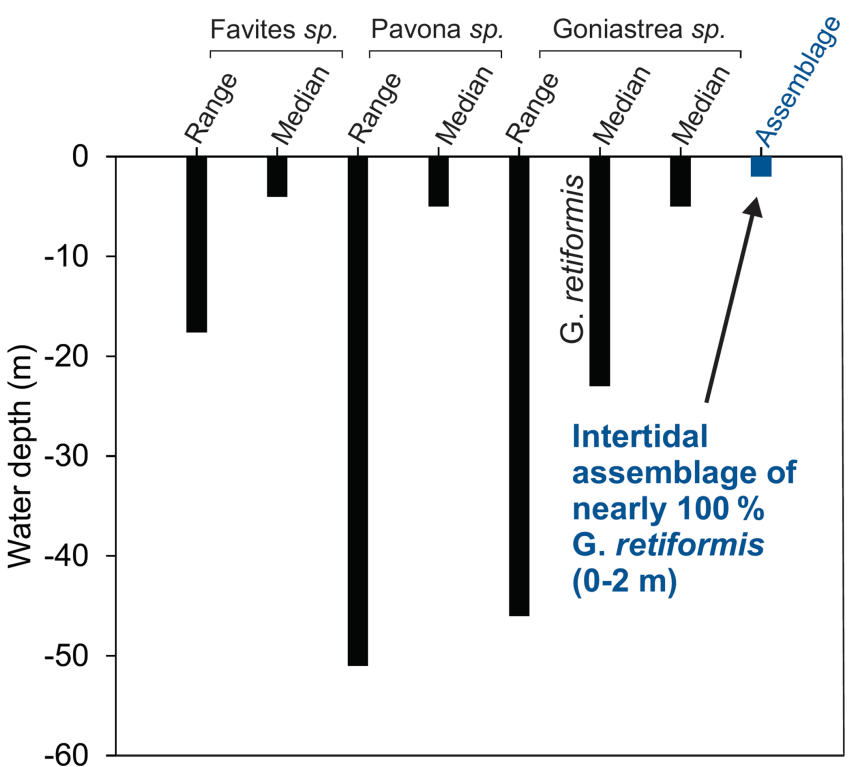

Figure 5. Comparison of approaches for interpreting sample paleowater depth based on modern coral depth distributions and reef assemblages for LIG fossil reef outcrops in the Seychelles. Modern depth distributions for the genera Favites, Pavona and Goniastrea (all of which are found in primary growth position in the Seychelles outcrops) are shown by the black bars in terms of the median and total depth range (95\% confidence; OBIS, 2014). The blue bar is the paleowater depth interpretation for an intertidal assemblage that grew in $0-2 \mathrm{~m}$ water depth based on facies interpretations of the fossil reef outcrops and comparison to modern reef analogues (Dutton et al., 2015b).

1982). The assemblage approach is a powerful tool that can substantially reduce the paleowater depth uncertainty for LIG fossil reef sites. Assigning paleowater depth ranges based on fossil reef assemblages does, however, involve a certain degree of subjectivity. Therefore, users of assemblage-derived paleowater depth ranges should be aware that these interpretations may change after a study's original publication date if new stratigraphic context and more robust modern and/or paleoecological studies become available. These are included to help define the paleowater depth uncertainty where possible.

A second approach relies upon modern coral depth distributions to parameterize paleowater depth uncertainty (e.g., Hibbert et al., 2016). A significant drawback of using modern depth distributions is that relying upon the full range of growth can greatly overestimate the true depth relative to actual paleo-sea-level position, as many corals can grow in a wide range of water depths. For example, individual colonies of the Caribbean coral species Acropora palmata have been found growing in water depths up to $22 \mathrm{~m}$ in modern reef environments, but this species is more commonly associated with reef crest environments that are $<5 \mathrm{~m}$ water depth, with a median depth occurrence of $-1.5 \mathrm{~m}$ (Lighty et al., 1982; OBIS, 2014). If field evidence shows that a dated coral was 
part of a Acropora palmata facies where the colonies are in primary growth position, this strengthens the argument that the coral was growing in the $<5 \mathrm{~m}$ water depth as opposed to closer to the maximum depth range. Therefore, relying on modern coral depth distributions can, in many cases, substantially overestimate the true water depth a fossil coral colony was growing in, and these depth distributions are not a substitute for detailed paleoecological and facies analysis. This is especially true for colonies sampled at or near the highest occurrence of LIG reef deposits, which were likely growing at the shallower end of their depth ranges.

Whenever possible, we used assemblage-derived paleowater depth estimates, which came from either the original publication or reinterpretations from a subsequent study. If no paleowater depth constraints were available, then we applied the taxon-based modern water depth distributions instead (i.e., the median, upper and lower water depth limits for the $95 \%$ confidence level from OBIS, 2014). All paleowater depth interpretations are current as of the date of publication, but users are cautioned that some of these interpretations will likely need to be revisited in the future as new studies advance our understanding of LIG and modern reef ecology.

It should also be noted that in the online WALIS database template there are three values that must be given when assigning paleowater depth: (1) estimated paleowater depth and the (2) upper and (3) lower limit of this depth estimate. In the user interface, the upper depth limit is listed first, followed by the estimated paleowater depth and lower limit, with all depths entered as negative numbers. The estimated paleowater depth does not necessarily have to be the midpoint of the interpreted depth range (e.g., a coral collected from an Acropora palmata reef crest facies with an estimated paleowater depth of $<5 \mathrm{~m}$ is parameterized as $[-5,0,-5]$, where the first term represents the position below the sea surface and the following two terms represent the uncertainty $(+,-)$ ). For simplicity's sake, in the main text this will be written as $5+0 /-5 \mathrm{~m}$.

\subsection{Further elevation uncertainty: causes for RSL departures from GMSL}

In general, site-specific fossil reef RSL histories for the LIG diverge from GMSL because of processes such as regional tectonics, glacial isostatic adjustment (GIA) and dynamic topography (Broecker et al., 1968; Farrell and Clark, 1976; Mitrovica and Milne, 2003; McMurtry et al., 2010; Austermann et al., 2017). Although correcting fossil coral RSL records for these processes was not the main focus of this study, it is nonetheless important for a user to be cognizant of this complication when comparing sea-level records from different sites. It is also worth keeping in mind that, although all three factors affect the uncertainty in the absolute elevation for coral-derived RSL reconstructions, the relative contribution of each varies from site to site.

\subsubsection{Tectonic uplift/subsidence}

Many of the seminal studies that utilized fossil coral RSL data come from uplifted fossil reef terraces such as those found in the island nation of Barbados and on the Huon Peninsula in Papua New Guinea (Broecker et al., 1968; Bender et al., 1979; Edwards et al., 1987a; Stein et al., 1993). These sites were targeted largely because the uplifted terraces facilitated easy sampling of core material without the need for scientific drilling and because the exposed outcrops enabled detailed facies analysis of the fossil reef morphology and paleoecology. In contrast, some locations in the WALIS database have experienced subsidence since the LIG. In many cases, these sites are located on volcanic hot-spot islands which are subsiding because of crustal loading (e.g., Camoin et al., 2001; Thomas et al., 2009).

The challenge of interpreting RSL records at tectonically active study sites is that the uplift rate must be well constrained to extract meaningful information about GMSL change. In many cases, previous workers estimated uplift/subsidence rates using the highest-growth-position coral from an LIG unit (e.g., McMurtry et al., 2010). The general formula used to correct for tectonic activity is

$E_{\text {corrected }}=E_{\text {measured }}-r t$,

where $E_{\text {corrected }}$ is the subsidence-corrected elevation, $E_{\text {measured }}$ is the present-day elevation, $r$ is rate of elevation change (positive if uplifted, negative if subsiding) and $t$ is the age of the sample. The rate of uplift/subsidence is itself determined by

$r=\frac{\left(E_{\mathrm{max}}-E_{\mathrm{LIG}}\right)}{t_{\mathrm{LIG}}}$,

where $E_{\max }$ is the elevation of the highest-growth-position coral (regardless of whether the coral has a U-series age), $E_{\text {LIG }}$ is the peak elevation of the LIG highstand based on GMSL and $t_{\text {LIG }}$ is the timing of the LIG highstand. This approach, however, does not yield the true uplift/subsidence rate attributable to local tectonics and/or volcanic loading. This is because (1) there is still considerable uncertainty surrounding the actual $E_{\text {LIG }}$ value and (2) even if this value was well-constrained, both local RSL and the timing of LIG highstand would still often depart from $E_{\mathrm{LIG}}$ and $t_{\mathrm{LIG}}$ because of GIA effects (Creveling et al., 2015). Therefore, uplift/subsidence rates in this study are included for conceptual purposes only, as uplift/subsidence-corrected coral elevations do not typically provide precise absolute elevation constraints for the position of past sea level.

Values used for $E_{\mathrm{LIG}}$ and $t_{\mathrm{LIG}}$ vary from study to study, so we standardized the dataset by recalculating $r$ and $E_{\text {corrected }}$ for tectonically active sites using a value of $7.5 \pm 1.5 \mathrm{~m}$ for $E_{\mathrm{LIG}}$ and $123 \pm 6 \mathrm{kyr}$ for $t_{\mathrm{LIG}}$ based on the midpoint of LIG timing and magnitude given by Dutton et al. (2015a). Interpreted uplift/subsidence are not prescriptive, and these cor- 
rections should be reevaluated as new information becomes available.

\subsubsection{Glacial isostatic adjustment}

The advance and retreat of large continental ice sheets during the last glacial cycle caused long-lasting, global perturbations to the Earth's gravity field and rotation that persist to this day (Farrell and Clark, 1976; Mitrovica and Milne, 2003). This phenomenon, called glacial isostatic adjustment, can cause meter-scale changes in RSL at fossil reef sites that must be addressed to extract meaningful GMSL information for fossil coral sea-level indicators (Dutton et al., 2015a). Indeed, the 6-9 $\mathrm{m}$ estimate for the peak magnitude of the LIG highstand has been inferred from global compilations of RSL records that were corrected for GIA effects (Dutton and Lambeck, 2012; Kopp et al., 2009).

The magnitude of the difference between RSL and GMSL at fossil reef sites is spatially variable, depending in part on the proximity to past continental ice sheets. For instance, GIA modeling predicts a gradient in RSL across the circumCaribbean region, as many of the sites were sitting atop or proximal to the peripheral bulge of the Marine Isotope Stage (MIS) 6 ice sheet that covered North America (Dutton and Lambeck, 2012). This is supported by recent field surveys from The Bahamas, which revealed a $\sim 1 \mathrm{~m}$ difference between the highest-primary-growth-position corals from LIG deposits on San Salvador and Great Inagua Island (Skrivanek et al., 2018). In contrast, so-called "far-field" sites such as the Seychelles and Western Australia are located much farther from continental ice sheets, which reduces the influence of GIA and thus enables them to more closely track the magnitude of GMSL change during the LIG (e.g., Dutton et al., 2015b; O'Leary et al., 2013; Stirling et al., 1998). This remains an active area of research, particularly for constraining the global extent and retreat of MIS 6 ( 136-129 kyr) continental ice sheets (Clark et al., 2020; Creveling et al., 2015; Dendy et al., 2017; Hay et al., 2014).

\subsubsection{Dynamic topography}

Dynamic topography is vertical displacement of the solid earth caused by mantle convection. Previous work demonstrated that the effect of dynamic topography on million-year timescales is of a similar order of magnitude to apparent changes in GMSL inferred from RSL records (Moucha et al., 2008; Müller et al., 2008; Rowley et al., 2013). Recent work demonstrated that this is also the case for the LIG, in that dynamic topography can cause meter-scale differences in RSL between the LIG and the present day at some localities (Austermann et al., 2017). These studies clearly demonstrate that the effect of dynamic topography on LIG RSL records is nontrivial, and further work is needed to assess how mantle dynamic topography may affect interpretations of past sea level from fossil reef sites.
In summary, there are both local (tectonic) and globalscale (GIA, dynamic topography) processes that can cause RSL at a fossil reef site to depart from the global mean, and they must be accounted for to extract a robust GMSL signal using U-series ages and elevations of fossil corals. Although GIA and dynamic topography influence interpretation of RSL compared to GMSL, we do not provide those interpretations here. Instead, this study was undertaken to define RSL at each site so that robust RSL interpretations are available that can be used to constrain such processes and, by extension, GMSL.

\section{LIG fossil coral database}

An overview of the coral U-series ages available in the dataset is included below, organized alphabetically by geographic study area. Each entry, where appropriate, contains the following:

1. the total number of U-series ages available for the study area and the number of unique coral specimens dated;

2. whether any of the corals were dated in duplicate, triplicate, etc.;

3. how many ages were accepted by the original publication;

4. how many ages (if any) pass the flexible and strict screening protocols;

5. identification of corals that pass screening and are in primary growth position;

6. mention of previous interpretations of paleowater depth uncertainty and what water depth uncertainties were assigned by the present study;

7. whether the site is tectonically uplifting, subsiding or stable; and

8. whether the U-series ages have been discussed by other contributions to the WALIS special issue with regards to the broader geologic context at each locality.

A summary of the coral U-series ages that passed the strict and flexible screening protocol is provided in Supplement S1, and the flexible protocol is also coded into WALIS as the preferred screening protocol utilized in this paper.

In total, $141 \mathrm{U}$-series ages were accepted from 104 unique coral samples that passed the strict screening protocol, whereas 286 ages from 215 samples were accepted under the flexible protocol (Table 1). Of the samples that were treated as RSL indicators, 59 ages were accepted from 39 coral samples under the strict protocol, whereas 150 ages from 112 coral samples were accepted under the flexible protocol. Finally, for the marine-limiting samples, four ages 
from three coral samples were accepted under the strict protocol, whereas nine analyses from eight coral samples were accepted under the flexible protocol. We did not include coral U-series ages that were measured using the considerably less precise dating method of alpha spectrometry, but the ability to add alpha dates is present in the WALIS user interface. The addition of alpha spectrometry ages to this dataset by community members is encouraged, especially for sites where mass spectrometric $\mathrm{U}$-series measurements are not available.

\subsection{The Bahamas}

Corals were U-series-dated from emergent LIG reef deposits on Great Inagua, San Salvador and the Abaco Islands in The Bahamas (Chen et al., 1991; Hearty et al., 2007; Thompson et al., 2011). A total of $200 \mathrm{U}$-series ages from 142 unique coral specimens were reported, with 29 of these corals dated at least in duplicate. In total, the original study authors accepted 49 U-series ages from 37 coral samples as closedsystem ages. Thompson et al. (2011) did not use closedsystem ages and instead applied an open-system correction to each sample. Under the strict screening protocol, $35 \mathrm{U}$-series ages from 26 coral samples were accepted. This number increased to $43 \mathrm{U}$-series ages from 29 corals when the flexible screening protocol was applied. Sample ages that passed flexible screening ranged from $131.3 \pm 1.4 \mathrm{kyr}$ for $\mathrm{CH} 91-002$ to a weighted mean age of $119.8 \pm 0.3 \mathrm{kyr}$ for TH11-023 (weighted mean ages are reported where multiple subsamples of the same coral passed the screening criteria).

Several site-specific adjustments were made under the flexible screening protocol. First, the ${ }^{232} \mathrm{Th}$ concentrations for Chen et al. (1991) were recalculated using the published ${ }^{230} \mathrm{Th} /{ }^{232} \mathrm{Th}$ activity ratios from their supplement, as in certain cases only one ${ }^{232} \mathrm{Th}$ concentration was reported for multiple subsamples of the same coral. Second, we only considered samples that were dated at least in duplicate from Thompson et al. (2011), as calcite content was not reported in that study and there are no elevation data from which stratigraphic relationships can be derived. Finally, we accepted ages from sample CH91-023 as closed-system since the ages were reproducible and calcite content was on the cutoff threshold at $2 \%$.

Assessing whether corals from The Bahamas dataset were in primary growth position is challenging. Chen et al. (1991) applied the term "in situ" to describe both growth position corals that are part of the reef framework and detrital coral rubble that had been cemented in place. For the present compilation, we categorized all corals derived from rubble layers as "not in primary growth position". Using this approach, a total of 14 ages from Chen et al. (1991), derived from 11 coral specimens, can be treated as RSL indicators under the flexible screening protocol. Previous workers assigned a paleowater depth range of 3 to $4 \mathrm{~m}$ for the Cockburn Town and Devil's Point sites (Chen et al., 1991). A more recent study, however, reevaluated the vertical position and facies charac- teristics of the two fossil coral reefs using high-precision surveying techniques and published new paleowater depth interpretations (Skrivanek et al., 2018). It is difficult to compare the present dataset to the reef zones described in Skrivanek et al. (2018), as Chen et al. (1991) did not distinguish between reef units in their study. All of the corals in primary growth position, however, were colonies of Pseudodiploria clivosa or Orbicella annularis, which were found in units with interpreted paleowater depths of 0.2-5 $\mathrm{m}$ at Devil's Point reef and 0.2-3 $\mathrm{m}$ at Cockburn Town (Skrivanek et al., 2018).

Thompson et al. (2011) distinguished corals that were derived from a rubble layer from those collected from the in situ reef framework but gave no elevation information associated with each sample, so none of the samples are used as RSL indicators here. Though elevation estimates were provided in Thompson et al. (2011) for each reef unit, these elevations do not always match those subsequently surveyed at the same sites, calling into question the use of those approximate elevations (Skrivanek et al., 2018). Primary-growth-position corals can, however, still be used to constrain the maximum age of each fossil reef, even without published elevation data. A total of five corals (11 analyses in total) from Thompson et al. (2011) are in primary growth position and passed the flexible screening criteria. These ages range from $127.3 \pm 0.6$ to $119.8 \pm 0.3 \mathrm{kyr}$ for the Devil's Point reef and $125.2 \pm 1.5$ to $122.2 \pm 1.7 \mathrm{kyr}$ for the Cockburn Town reef.

\subsection{Baja California, Mexico}

U-series coral ages were reported for three locations along the Pacific coast of Baja California, Mexico (Muhs et al., 2002a). Corals collected for that study came from detrital sedimentary deposits on marine terraces and, therefore, were not in primary growth position and cannot be used as strictly reliable RSL indicators. Instead, the study authors used coral U-series ages as a constraint on the maximum age of the terraces. In total, 26 corals were dated, and the study authors accepted 16 of the U-series ages. None of these ages passed the strict or flexible closed-system criteria.

\subsection{Barbados}

Barbados is one of the most intensely studied LIG fossil reef localities in the world, with $141 \mathrm{U}$-series analyses reported for 107 corals from 11 separate studies (Bard et al., 1990; Blanchon and Eisenhauer, 2001; Cutler et al., 2003; Edwards et al., 1997, 1987b; Gallup et al., 1994, 2002; Hamelin et al., 1991; Muhs and Simmons, 2017; Speed and Cheng, 2004; Thompson et al., 2003). The island is located on an accretionary prism and has experienced differential uplift since the LIG. Local uplift rates vary from $\sim 0.2 \mathrm{~m} / \mathrm{kyr}$ in the north and south of Barbados to as high as $\sim 0.5 \mathrm{~m} / \mathrm{kyr}$ near the Clermont Nose/University of the West Indies transect near the middle of the island (e.g., Muhs and Simmons, 2017; Taylor and Mann, 1991), so care must be taken when applying 
Table 1. Summary of samples that passed closed-system screening protocols.

\begin{tabular}{|c|c|c|c|c|c|c|c|c|}
\hline \multirow[b]{2}{*}{ Location } & \multicolumn{2}{|c|}{ Total $^{*}$} & \multicolumn{2}{|c|}{ Published } & \multicolumn{2}{|c|}{ Strict (this study) } & \multicolumn{2}{|c|}{ Flexible (this study) } \\
\hline & Analyses & Samples & Analyses & Samples & Analyses & Samples & Analyses & Samples \\
\hline Bahamas & 200 & 142 & 49 & 37 & 35 & 26 & 43 & 29 \\
\hline Baja California & 26 & 26 & 16 & 16 & 0 & 0 & 0 & 0 \\
\hline Barbados & 141 & 107 & 40 & 33 & 24 & 17 & 41 & 28 \\
\hline Bermuda & 9 & 9 & 7 & 7 & 2 & 2 & 3 & 3 \\
\hline California & 153 & 148 & 34 & 32 & 0 & 0 & 4 & 3 \\
\hline Canary Islands & 2 & 2 & 2 & 2 & 0 & 0 & 0 & 0 \\
\hline Cabo Verde & 10 & 6 & 10 & 6 & 0 & 0 & 1 & 1 \\
\hline Curaçao & 25 & 5 & 5 & 4 & 1 & 1 & 4 & 3 \\
\hline Eritrea & 7 & 6 & 6 & 5 & 0 & 0 & 0 & 0 \\
\hline Florida & 55 & 51 & 15 & 13 & 4 & 3 & 13 & 10 \\
\hline French Polynesia & 19 & 12 & 6 & 3 & 5 & 3 & 9 & 5 \\
\hline Grand Cayman & 15 & 15 & 12 & 12 & 0 & 0 & 0 & 0 \\
\hline Great Barrier Reef & 40 & 14 & 11 & 5 & 3 & 2 & 7 & 3 \\
\hline Greece & 2 & 2 & 2 & 2 & 0 & 0 & 0 & 0 \\
\hline Gulf of Aqaba & 67 & 18 & 6 & 4 & 2 & 2 & 2 & 2 \\
\hline Haiti & 3 & 2 & 3 & 2 & 0 & 0 & 3 & 2 \\
\hline Hawaii & 82 & 72 & 59 & 52 & 25 & 23 & 34 & 29 \\
\hline Indonesia & 21 & 21 & 14 & 14 & 4 & 4 & 10 & 10 \\
\hline New Caledonia & 19 & 15 & 0 & 0 & 0 & 0 & 0 & 0 \\
\hline Niue & 1 & 1 & 1 & 1 & 0 & 0 & 0 & 0 \\
\hline Papua New Guinea & 47 & 34 & 11 & 7 & 11 & 5 & 13 & 7 \\
\hline Saudi Arabia & 25 & 25 & 17 & 17 & 1 & 1 & 2 & 2 \\
\hline Seychelles & 67 & 31 & 38 & 24 & 5 & 3 & 25 & 14 \\
\hline Southern Australia & 4 & 4 & 1 & 1 & 0 & 0 & 0 & 0 \\
\hline St. Croix, US Virgin Islands & 6 & 6 & 5 & 5 & 4 & 4 & 5 & 5 \\
\hline Turks and Caicos & 19 & 19 & 13 & 13 & 0 & 0 & 0 & 0 \\
\hline Vanuatu & 3 & 2 & 3 & 2 & 3 & 2 & 3 & 2 \\
\hline Western Australia & 176 & 156 & 59 & 55 & 9 & 5 & 61 & 56 \\
\hline Yemen & 35 & 33 & 0 & 0 & 0 & 0 & 0 & 0 \\
\hline Yucatán & 33 & 10 & 7 & 5 & 3 & 1 & 3 & 1 \\
\hline Total & 1312 & 994 & 452 & 379 & 141 & 104 & 286 & 215 \\
\hline
\end{tabular}

* Includes all reported analyses and samples (as opposed to the other three pairs of columns, which only include analyses that were accepted by the respective screening protocol)

subsidence corrections to the Barbados dataset. Additionally, the dataset can be challenging to interpret, as there are multiple names for some localities, and some coral samples have been dated in two or more studies. To facilitate data accessibility, we standardized site location names (e.g., all LIG samples from the Clermont Nose area were given the site name "Univ. West Indies (UWI) Transect"), and we endeavored to link U-series measurements across multiple studies that were derived from the same coral colony.

Of the U-series ages reported, the original study authors accepted 40 ages from 33 unique coral specimens. It should be noted that Thompson et al. (2003) did not apply closedsystem screening criteria; rather, an open-system model was used. Under the strict screening protocol, a total of $24 \mathrm{U}$ series ages were accepted from 17 corals, whereas the flexible protocol accepted 41 ages from 28 corals. Ages from the flexible screening protocol range from $103.8 \pm 1.0 \mathrm{kyr}$
(BL01-001-001) to $172.5 \pm 1.4 \mathrm{kyr}$ (GA02-006-001). The oldest age was sampled from "Lazaretto unit", which is part of the LIG Rendezvous Hill terrace, but this unit is actually MIS 6 in age (Speed and Cheng, 2004). It should be noted that one sample which passed both screening protocols, GA02-032-001 (136.4 $\pm 0.9 \mathrm{kyr})$, was rejected, as this age was eventually retracted by the Gallup et al. (2002) study authors after multiple dated subsamples from the same colony were unable to reproduce the reported age. Several of the corals were also dated using $\mathrm{Pa}-\mathrm{Th}$ methods (Cutler et al., 2003; Edwards et al., 1997; Gallup et al., 2002).

Of the samples that passed flexible screening, a total of eight $U$-series ages (six corals in total) came from corals that were stated as being in primary growth position, with ages ranging from $103.8 \pm 1.0 \mathrm{kyr}$ (BL01-001) to $172.5 \pm 1.4 \mathrm{kyr}$ (GA02-006). The number of RSL data points is increased to 29 ages from 21 corals by including all samples that were 
not explicitly identified as transported clasts or cobbles. One primary-growth-position coral with an age of $129.6 \pm 0.8 \mathrm{kyr}$ (GA02-014) was treated as marine limiting as no coral taxonomic information was provided. In cases where primarygrowth-position corals are derived from a reef crest facies, we assigned a paleowater depth of $<5 \mathrm{~m}$, which is the typical depth range for modern Caribbean reef crest environments (Lighty et al., 1982). In all other cases, we applied the taxon-derived modern depth distributions (OBIS, 2014).

\subsection{Bermuda}

LIG-aged corals are present at Grape Bay on the southern side of Bermuda (Ludwig et al., 1996; Muhs et al., 2002b). These deposits are inferred to be originally derived from patch reefs but are not in primary growth position and may have been storm derived (Muhs et al., 2002b). Therefore, the ages presented in these studies represent a constraint on the maximum age of the rubble deposit but cannot be used as RSL indicators. In total, nine corals were dated from Grape Bay, and the authors originally accepted seven of the ages. Only two corals pass the strict closed-system criteria: MU02-019, with an age of $116.9 \pm 0.9 \mathrm{kyr}$, and MU02020 , with an age of $113.7 \pm 0.9 \mathrm{kyr}$. A third coral, MU02-026 $(118.7 \pm 0.9 \mathrm{kyr})$, is also accepted once the flexible protocol has been applied.

\subsection{California, United States}

Several studies reported U-series coral ages from marine deposits along the southwest coast of California and several of the Channel Islands (Muhs et al., 2012a, 2006, 2002b; see global review of MIS 5a/c sea-level records by Thompson and Creveling (2021) for an overview of MIS 5 marine terraces along the California coast). These samples are solitary Balanophyllia elegans corals from detrital sedimentary deposits on marine terraces and are therefore not in primary growth position and cannot be used as RSL indicators. Instead, the study authors used the coral U-series ages as a constraint on the maximum age of terrace formation. A total of $153 \mathrm{U}$-series ages were reported for 148 unique coral specimens, with four of the corals dated in duplicate. The study authors accepted 34 of the ages ( 32 corals in total). None of the ages passed the strict closed-system criteria, but four ages from three corals were accepted under the flexible protocol: MH02-075 (118.3 $\pm 0.6 \mathrm{kyr})$, MH02$077(119.9 \pm 0.8 \mathrm{kyr}$ ) and MH06-013 (weighted mean age of $118.8 \pm 0.7 \mathrm{kyr})$.

\subsection{Canary Islands}

Two LIG ages are reported from Gran Canaria and Lanzarote in the Canary Islands (Muhs et al., 2014). Both corals were Siderastrea radians fragments collected from marine deposits and were used to determine the maximum age of the deposits and constrain local uplift rates. The authors accepted both ages, assigned a $0.017-0.050 \mathrm{~m} / \mathrm{kyr}$ uplift rate for the Gran Canaria site and determined that the Lanzarote site had not been subjected to significant uplift since the LIG. Neither age passed the strict or the flexible screening protocols, but they do broadly constrain the age of their respective deposits to the LIG.

\subsection{Cabo Verde}

Zazo et al. (2007) reported U-series coral ages that were used to constrain the age of marine terrace conglomerates on Sal Island, Cabo Verde. In total, 10 U-series ages were reported for five corals (and one hydrozoan), with one coral sample (ZA07-004) analyzed five times. All coral ages were accepted by the study authors, but only one age from coral ZA07-004 $(129.5 \pm 4.0 \mathrm{kyr})$ passed the flexible protocol. This coral is not in primary growth position and cannot be used to constrain RSL.

\subsection{Curaçao}

U-series ages have been reported for multiple outcrops of the LIG Hato unit on the island of Curaçao, for a total of 25 ages from 15 unique coral colonies (Hamelin et al., 1991; Muhs et al., 2012b; for a regional overview, see Rubio-Sandoval et al., 2021). Curaçao is slowly uplifting, with an estimated uplift rate of 0.026 to $0.054 \mathrm{~m} / \mathrm{kyr}$, based on the "highest inner edge" elevation of the Hato unit at $12.4 \mathrm{~m}$ (Muhs et al., 2012b). In total, the study authors accepted five U-series ages from four unique coral specimens. Under the strict screening protocol, this is reduced to a single age of $118.8 \pm 0.8 \mathrm{kyr}$ from sample SC78-005-002. The flexible protocol adds three additional ages: two from MU12-001, with a weighted mean age of $126.6 \pm 0.7 \mathrm{kyr}$, and an age of $118.7 \pm 1.2 \mathrm{kyr}$ from coral SC78-002-002.

All samples which passed the flexible screening criteria were in primary growth position. Based on the paleoenvironmental interpretations of Muhs et al. (2012b), samples SC78-005 and MU12-001 were part of an Acropora palmatadominated reef crest facies growing in $0-5 \mathrm{~m}$ water depth, which we adopted for this study. Paleoenvironmental interpretations and stratigraphic context were not provided for sample SC78-002. Therefore, the modern depth distribution for Diploria spp. was applied in this case (OBIS, 2014).

\subsection{Eritrea}

Fossil corals of LIG age were reported for the Abdur Reef Limestone on the Red Sea coast of Eritrea (Walter et al., 2000). The Eritrean coast is tectonically active and is estimated to be uplifting by $0.06 \mathrm{~m} / \mathrm{kyr}$ based on the elevation of the LIG reef deposits (Hibbert et al., 2016). In total, seven U-series ages were reported for six corals, with one coral dated in duplicate. In the original study, the authors accepted 
all ages, except for one from coral WA00-006, which had anomalously low $\mathrm{U}$ content and an age that was older than expected. None of the ages passed the strict or the flexible closed-system screening criteria.

\subsection{Florida, United States}

Fossil corals have been dated from multiple sites across the Florida Keys (Fruijtier et al., 2000; Muhs et al., 2011; Multer et al., 2002). In total, 55 U-series ages were reported for 51 unique coral samples, with four corals dated in duplicate. In total, the study authors accepted 15 of the ages from 13 coral samples. Under the strict screening criteria, four ages were accepted from three unique coral specimens from Windley Key: MU11-026, with a weighted mean age of $115.1 \pm 0.6 \mathrm{kyr}$; MU11-034, with an age of $114.1 \pm 0.6 \mathrm{kyr}$; and MU11-037, with an age of $120.4 \pm 0.8 \mathrm{kyr}$. Using the flexible screening protocol, the total number of analyses accepted increases to 13 , from a total of 10 unique coral specimens ranging from a weighted-mean age of $123.0 \pm 0.6 \mathrm{kyr}$ (MU11-012) to a weighted-mean age of $113.7 \pm 0.6 \mathrm{kyr}$ (MU11-034). One of these samples, MU11-005, was accepted despite failing the strict ${ }^{232} \mathrm{Th}$ criterion, as it was only marginally higher $(2.4 \mathrm{ppb})$ and passed both the calcite and $\delta^{234} \mathrm{U}_{\mathrm{i}}$ thresholds. It should be noted that samples from Muhs et al. (2011) and Multer et al. (2002) appeared to have a $5 \%$ limit of quantification for their XRD techniques, so all samples from these studies were interpreted as having acceptable calcite content.

All 10 corals that passed the flexible screening protocol were in primary growth position and, therefore, can be used as RSL indicators. These samples were collected from outcrops of the Key Largo Limestone at Windley Key and Key Largo, with sample elevations ranging from 2-5 ma.m.s.l. (Muhs et al., 2011). The dominant coral taxa in the outcrops studied at both localities were massive Orbicella annularis and Pseudodiploria strigosa, with the Windley Key site also containing Colpophyllia natans. Several estimates of paleowater depth for the Key Largo Limestone have been published and range from $<3 \mathrm{~m}$ to as much as $12 \mathrm{~m}$ water depth (Fruijtier et al., 2000; Muhs et al., 2011; Perkins, 1977; Stanley, 1966). Most recently, Muhs et al. (2011) interpreted this facies as having a minimum water depth of $3 \mathrm{~m}$ based on the optimal depth range for these three coral species from a modern ecological survey of reefs in the Florida Keys and Dry Tortugas (Shinn et al., 1989).

We adopted the $3 \mathrm{~m}$ estimate of Muhs et al. (2011) as the most probable paleowater depth for the LIG deposits at Key Largo and Windley Key and further parameterized the possible range of paleowater depths. As stated by Muhs et al. (2011), the optimum water depths for Pseudodiploria strigosa and Copophyllia natans are 3-10 and 2-10 m, respectively, whereas the optimal depth range for Orbicella annularis is substantially wider, at 3-45 m (Shinn et al., 1989). However, the modern Montastrea annularis distribution has a median depth closer to $10 \mathrm{~m}$ (upper $95 \%$ confidence inter$\mathrm{val}=17 \mathrm{~m}$ water depth; OBIS, 2014). Given this additional information, we parameterized the paleowater depth uncertainty for these samples as $3+7 /-0 \mathrm{~m}$.

\subsection{French Polynesia}

A regional overview of LIG sea-level records for French Polynesia is provided by Hallmann et al. (2020). Many of the islands and archipelagos in French Polynesia are former hotspot volcanoes that are subsiding because of volcanic loading. In these cases, LIG deposits are often located below sea level and can only be accessed via scientific drilling. U-series ages from corals have been published from two locations in French Polynesia: Mururoa atoll in the Tuamotu Archipelago and offshore drilling at Tahiti during IODP Expedition 310 (Camoin et al., 2001; Thomas et al., 2009). Both Mururoa Atoll and Tahiti have been subject to subsidence since at least the Late Pleistocene. The subsidence rate at Mururoa was estimated to be $\sim 0.07-0.08 \mathrm{~m} / \mathrm{kyr}$ using $\mathrm{K}-\mathrm{Ar}$ dating of the volcanic basement and the location of the LIG unit, which was $3 \mathrm{~m}$ below the modern reef (Trichet et al., 1984; Camoin et al., 2001). At Tahiti, the subsidence rate is an order of magnitude greater and is commonly estimated to be $0.25 \mathrm{~m} / \mathrm{kyr}$ with a total possible range of $0.2-0.4 \mathrm{~m} / \mathrm{kyr}$ (Le Roy, 1994; Bard et al., 1996; Thomas et al., 2012). To date, no corals of LIG age have been discovered at Tahiti, but several corals from the IODP record have been dated to late MIS 6 (Thomas et al., 2009).

The existing dataset for French Polynesia contains $19 \mathrm{U}-$ series dates from 12 corals, with five corals from Tahiti dated in duplicate and one in triplicate. Of the six corals analyzed from Mururoa, only one age (CA01-007) was accepted by the study authors. This sample also passed the strict screening protocol and has a recalculated age of $126.0 \pm 2.2 \mathrm{kyr}$. For the samples from Tahiti, two corals (TH09-001 and TH09-003) were accepted by the study authors. Based on the strict screening protocol, dates from two corals and four unique U-series measurements passed screening: TH09-003, with a weighted-mean age of $133.9 \pm 0.4 \mathrm{kyr}$, and TH09-008, with a single age of $134.0 \pm 0.4 \mathrm{kyr}$. By employing the flexible screening protocol, four additional U-series ages can be included from two corals: TH09-001 (weighted mean age of $138.0 \pm 0.5 \mathrm{kyr}$ ) and TH09-005 (weighted mean age of $137.0 \pm 0.5 \mathrm{kyr})$.

Sample CA01-007 from Mururoa was reported as being "reworked" (Camoin et al., 2001). Samples TH09-001, TH09-003, TH09-005 and TH09-008 are both interpreted as being in growth position and thus can be used as RSL indicators. TH09-003 and TH09-008 are both massive Porites spp., which is commonly associated with depth ranges of 0 $25 \mathrm{~m}$, while TH09-001 and TH09-005 were associated with a shallower facies interpreted as growing in $0-6 \mathrm{~m}$ water depth (Thomas et al., 2009). 


\subsection{Grand Cayman, Cayman Islands}

Fossil corals have been dated from multiple localities across Grand Cayman (Coyne et al., 2007; Vezina et al., 1999). In total, 15 corals from the LIG and late MIS 6 were dated, with the authors accepting all but three ages. All of the ages were rejected by the strict and flexible closed-system screening protocols.

\subsection{The Great Barrier Reef, Australia}

Two studies have reported LIG U-series ages from the Great Barrier Reef, which were collected via scientific drilling on modern reef flats (Braithwaite et al., 2004; Dechnik et al., 2017). A total of 40 ages from 14 unique coral specimens were reported, and the authors originally accepted 11 of the ages from five corals. All but one of these corals (BR04-001) were dated in triplicate. Under the strict screening protocol, three ages were accepted from two coral samples (DE17001, DE17-003). When the flexible protocol was applied, the total number of accepted ages expanded to include seven ages from three corals: DE17-001, with a weighted mean age of $128.7 \pm 0.7 \mathrm{kyr}$; a single age from DE17-003, which was dated to $126.1 \pm 0.5 \mathrm{kyr}$; and DE17-004, with a weighted mean age of 127.7 $\pm 0.5 \mathrm{kyr}$. Coral DE17-004 had higher calcite content $(6.5 \%)$ but was nevertheless accepted because the ages were stratigraphically consistent with DE17$001 / 003$ and the sample passed the ${ }^{232} \mathrm{Th}$ and $\delta^{234} \mathrm{U}_{\mathrm{i}}$ thresholds.

All three corals that passed the flexible screening protocol were in primary growth position and can be used as RSL indicators. Using the coralgal assemblage interpretations, Dechnik et al. (2017) assigned these samples a 0-6 m paleowater depth range, which we also adopted.

\subsection{Greece}

One study reported corals with LIG ages from uplifted terraces on the Perachora Peninsula, Greece, which were originally used to constrain local uplift rates (Dia et al., 1997). The authors reported that the two corals with LIG ages (DI97-002, DI97-003) showed signs of open-system behavior, based on uranium isotopes $\left(\delta^{234} \mathrm{U}_{\mathrm{i}}>200 \%\right.$ ) , high detrital ${ }^{232} \mathrm{Th}$ concentrations $(\sim 7 \mathrm{ppb})$ and anomalously low ${ }^{87} \mathrm{Sr} /{ }^{86} \mathrm{Sr}$ ratios. DI97-002 and DI97-003 passed neither the strict nor the flexible closed-system screening criteria.

\subsection{Gulf of Aqaba}

Three studies reported U-series ages on corals from uplifted terraces along the Gulf of Aqaba (Bar et al., 2018; Manaa et al., 2016; Yehudai et al., 2017). Bar et al. (2018) inferred an uplift rate of $0.13 \mathrm{~m} / \mathrm{kyr}$ for the northeastern Gulf of Aqaba based on the present-day elevation of the coral terraces and the timing of diagenesis for altered fossil corals dated by Yehudai et al. (2017). In total, $67 \mathrm{U}$-series ages were reported for 18 unique coral specimens, with the majority of samples dated in triplicate or greater. In total, the study authors accepted six of these ages from four coral samples. Under both the strict and flexible closed-system screening criteria, only two samples were accepted from the upper Haql terrace: MA16-003, with an age of $119.7 \pm 0.5 \mathrm{kyr}$, and MA16-004, with an age of $120.2 \pm 0.6 \mathrm{kyr}$.

It is unclear which coral samples were collected in primary growth position, so MA16-003 and MA16-004 were not treated as RSL indicators within the database.

\subsection{Haiti}

Bard et al. (1990) reported U-series ages from the northwest coast of Haiti. In total, three analyses were conducted on two unique coral specimens, with one of the corals dated in duplicate. All three ages were accepted by the study authors, but detrital Th content was not reported, which meant we were unable to accept the ages based on the strict screening protocol. Under the flexible protocol, all three ages were accepted from two corals: BA90-021 (122.8 $\pm 1.1 \mathrm{kyr})$ and BA90-022 (weighted mean age of $125.3 \pm 1.4 \mathrm{kyr}$ ). Both samples were identified as Acropora palmata corals that were part of a reef crest facies, which typically grows in $<5 \mathrm{~m}$ water depth (Lighty et al., 1982). The northeastern coastline of Haiti is tectonically active, and it is estimated that the uplift rate is approximately $0.36 \mathrm{~m} / \mathrm{kyr}$ based on the elevation of the local LIG terrace reported by Dodge et al. (1983).

\subsection{Hawaii, USA}

Several studies have published coral U-series ages from the Waimanalo Formation on the Hawaiian island of Oahu, which dates to the LIG (Hearty et al., 2007; McMurtry et al., 2010; Muhs et al., 2002b; Szabo et al., 1994; for a regional overview, see Hallmann et al., 2020). Oahu is slowly uplifting at a rate of $\sim 0.06 \mathrm{~m} / \mathrm{kyr}$ because it is located on the peripheral bulge of the island of Hawaii, which is subsiding as a consequence volcanic loading from Hawaiian hot-spot volcanism (McMurtry et al., 2010, and references therein; Szabo et al., 1994). A total of $82 \mathrm{U}$-series analyses were published for Oahu from 72 unique coral specimens. Eight of the samples have been dated in duplicate and one in triplicate.

In the original studies, the authors accepted 59 ages from 52 coral samples, whereas under the strict screening protocol we accepted 25 U-series ages from 23 coral samples. Using the flexible screening protocol, this number increased to 34 ages from 29 coral samples, with ages ranging from $110.84 \pm 3.9 \mathrm{kyr}$ (SZ94-007) to 133.0 $\pm 3.3 \mathrm{kyr}$ (SZ94-021). The ${ }^{232} \mathrm{Th}$ concentrations for Szabo et al. (1994) were recalculated using the published ${ }^{230} \mathrm{Th} /{ }^{232} \mathrm{Th}$ activity ratios. Additionally, we interpreted the limit of quantification for the XRD measurements in Szabo et al. (1994) to be $5 \%$ for calcite, which led to two additional ages (SZ94-002-001, SZ94016-001) being accepted. 
Many of the dated samples from Oahu were either clasts or collected from marine conglomerates, so the number of samples that can be used as RSL indicators is substantially smaller than the total number of corals that passed screening. Under the flexible protocol, a total of nine corals can be treated as RSL indicators, with ages ranging from $110.8 \pm 3.9 \mathrm{kyr}$ (SZ94-007) to $126.5 \pm 0.7 \mathrm{kyr}$ (MU02-055). The only constraint on paleowater depth was given in Szabo et al. (1994), in which the authors noted that typical water depths for Pacific Pocillopora and Porites are between 1 and $27 \mathrm{~m}$ based on a previous synthesis paper (Wells, 1954). Both Szabo et al. (1994) and Muhs et al. (2002b), however, ultimately treated primary-growth-position corals as marine limiting, with a minimum water depth of $1 \mathrm{~m}$. Without any additional constraints on water depth, we applied the taxonspecific modern coral depth distributions (OBIS, 2014).

\subsection{Indonesia}

Coral U-series ages were reported for two locations in Indonesia: Sumba Island and Southeast Sulawesi (Bard et al., 1996; Pedoja et al., 2018; see Maxwell et al., 2021, for a regional overview). Both locations are tectonically active, with uplift rates for Sumba Island and Southeast Sulawesi estimated by the study authors to be $0.2-0.5$ and $0.12-$ $0.29 \mathrm{~m} / \mathrm{kyr}$, respectively. Between these two study sites, a total of 21 corals were dated, and 14 of these ages were accepted by the study authors. Based on the strict closedsystem criteria, four of the ages from Pedoja et al. (2018) were accepted: PE18-001, with an age of $133.7 \pm 3.0 \mathrm{kyr}$; PE18-002, with an age of 131.2 $\pm 3.0 \mathrm{kyr}$; PE18-005, with an age of $112.8 \pm 3.0 \mathrm{kyr}$; and PE18-008, with an age of $127.8 \pm 2.0 \mathrm{kyr}$. Under the flexible criteria, six additional ages were accepted from Bard et al. (1996), ranging from $86.9 \pm 0.6 \mathrm{kyr}$ (BR96-008) to $133.1 \pm 1.0 \mathrm{kyr}$ (BR96-012).

Although sample elevations for Pedoja et al. (2018) were reported, the elevation uncertainty is large $( \pm 10 \mathrm{~m})$, and the authors did not provide facies information or state whether the corals were in primary growth position. All six Bard et al. (1996) ages were identified as primary-growth-position corals. Sample BR96-016 was originally interpreted as growing in $5-15 \mathrm{~m}$ water depth, so we have used the midpoint of this range as the assigned paleowater depth uncertainty (i.e., $10+5 /-5 \mathrm{~m}$ ). The other five ages were not associated with facies/paleowater depth interpretations, so the modern taxa depth distributions were assigned (OBIS, 2014). However, it should be noted that sample BR96-017 was identified as a Porites microatoll, which implies that the colony was likely growing within the subtidal/intertidal zone.

\subsection{New Caledonia}

One study reported U-series ages from corals cored on Amédée Islet, New Caledonia (Frank et al., 2006; for regional review, see Hallmann et al., 2020). In total, 19 anal- yses were reported for 15 corals, with one coral dated five times. The study authors used open-system ages (Thompson et al., 2003; Villemant and Feuillet, 2003) to confirm the existence of an LIG reef deposit within the core records and estimated a subsidence rate of $0.16 \mathrm{~m} / \mathrm{kyr}$ for the study site. The strict and flexible closed-system criteria rejected all of the ages from New Caledonia.

\subsection{Nive}

A single coral with a late MIS 6 age (KE12-001; $133.5 \pm 1.0 \mathrm{kyr}$ ) was reported for the South Pacific island of Niue and has been interpreted as a $2 \mathrm{~m}$ high Porites colony that infilled a karstic channel (Kennedy et al., 2012; for a regional overview, see Hallmann et al., 2020). The authors interpreted this deposit as being LIG in age. This U-series age, however, has an anomalously low initial uranium isotopic value $\left(\delta^{234} \mathrm{U}_{\mathrm{i}}=121.7 \pm 3.3 \%\right.$ ) ) and fails both the strict and flexible closed-system screening criteria.

\subsection{Papua New Guinea}

LIG fossil coral U-series ages are available from uplifted coral reef terraces on the Huon Peninsula, Papua New Guinea (Cutler et al., 2003; Esat et al., 1999; Stein et al., 1993; for a regional overview, see Hallmann et al., 2020). The region has experienced substantial uplift since the LIG, with local uplift rates estimated to be $\sim 2 \mathrm{~m} / \mathrm{kyr}$. As a result, the LIG fossil reef deposits are presently located $\sim 140-230 \mathrm{~m}$ a.m.s.l. A total of 47 analyses were reported from Huon Peninsula fossil reefs from 34 unique coral specimens. One coral was dated in duplicate, and five corals have U-series ages from multiple subsamples. Of the $47 \mathrm{U}$-series analyses performed, the study authors accepted 11 ages from seven coral samples (although the actual number of ages accepted is likely higher, as Esat et al. (1999) did not specify the acceptable $\delta^{234} \mathrm{U}_{\mathrm{i}}$ thresholds used in their study). Under the strict screening protocol, 11 ages from five coral samples (CU03-011, ST93-005, ST93-006, ST93-007, ST93-009) were accepted, whereas 13 ages from seven samples (CU03-011, CU03023, ES99-020, ST93-005, ST93-006, ST93-007, ST93-009) were accepted under the flexible protocol. The ages that pass the flexible screening protocol range from a weighted mean age of $115.2 \pm 0.7 \mathrm{kyr}$ for CU03-011 to $136.8 \pm 1.8 \mathrm{kyr}$ for a single analysis from ST93-006.

Corals CU03-011, CU03-023 and ES99-020 do not have any contextual information that can be used to determine if they are in primary growth position, so we did not treat these samples as RSL indicators. ST93-005, ST93-006, ST93-007 and ST93-009 are in primary growth position, but there are no published paleowater depth interpretations provided. Additionally, there are insufficient modern observations for Gardineroseris planulata to produce a robust modern depth distribution for these samples, so samples ST93-005 through ST93-007 can only be treated as marine limiting (Hibbert 
et al., 2016; OBIS, 2014). The final sample, ST93-009, is a colony of Porites lutea, which has a modern depth range of 0 $+0 /-45$ m (OBIS, 2014).

\subsection{Saudi Arabia}

One study published coral U-series ages for emergent coral reef terraces along the Red Sea coast of Saudi Arabia (Manaa et al., 2016). In total, study authors reported U-series ages for 25 coral samples and accepted 17 of the ages. Using the strict closed-system screening criteria, that number is reduced to three samples collected from reef terraces near the port city of Yanbu. Two of the samples (MA16-009 and MA16-010) were collected from the lower Yanbu terrace and yielded ages of $42.2 \pm 0.1$ and $51.4 \pm 0.1 \mathrm{kyr}$, respectively, but were rejected because the ages were not stratigraphically consistent with the rest of the unit (Manaa et al., 2016). The remaining age, from the upper Yanbu terrace (MA16-013), yielded an LIG age of $127.9 \pm 0.4 \mathrm{kyr}$. A second sample from the upper Yanbu terrace (MA16-012) was also accepted under the flexible screening protocol, yielding an age of $112.6 \pm 0.3 \mathrm{kyr}$. The authors did not state whether these samples were in primary growth position, so these samples were not treated as RSL indicators.

\subsection{The Seychelles}

Two studies from the Seychelles published U-series coral ages (Dutton et al., 2015b; Israelson and Wohlfarth, 1999; for a regional overview, see Boyden et al., 2021), containing a total of $67 \mathrm{U}$-series measurements for 31 individual coral specimens. Approximately half (15) of the corals were dated in triplicate, with three corals measured in duplicate. In the original studies, 24 of the corals yielded acceptable ages ( 38 unique U-series ages). Under the strict screening protocol, only five unique U-series ages from three corals are accepted. This is increased to $25 \mathrm{U}$-series ages from 14 corals once the flexible screening criteria are applied, with ages ranging from a weighted mean age of $122.2 \pm 0.5 \mathrm{kyr}$ from sample DU15017 to $129.1 \pm 1.6 \mathrm{kyr}$ from sample IS99-007.

Multiple sources have interpreted the Seychelles deposits as having formed in an intertidal to upper subtidal zone, which, based on modern analogues from these same islands, results in a maximum water depth of $2 \mathrm{~m}$ (Dutton et al., 2015b; Israelson and Wohlfarth, 1999; Montaggioni and Hoang, 1988). Here, the maximum paleowater depth of $2 \mathrm{~m}$ was adopted, with one exception. Sample IS99-010, a Porites sp., was not explicitly tied to the subtidal facies. Therefore, we assigned IS99-010 a water depth uncertainty based on the modern depth distribution for Porites spp. $(4+62 /-4 \mathrm{~m}$; OBIS, 2014). Of the 14 samples that met the flexible closedsystem screening criteria, all except DU15-017 and DU15019 were identified as being in primary growth position.

\subsection{South Australia}

LIG coral ages were reported for subtidal deposits on the Yorke Peninsula near Adelaide, South Australia (Pan et al., 2018). Four U-series ages were reported by the authors from four unique specimens of the solitary coral Plesiastrea versipora. One of the ages (PA18-002) was originally accepted by the authors, but none of the four samples met the strict or the flexible closed-system screening criteria. The Plesiastrea versipora were not in primary growth position, and these deposits were interpreted by Pan et al. (2018) as being wave and/or storm derived.

\subsection{St. Croix, US Virgin Islands}

In the US Virgin Islands, sediment cores from Holocene reefs off the island of St. Croix possess LIG reef deposits in the underlying substrate (Toscano et al., 2012). St. Croix is unique among many other Caribbean LIG sites in that all but one of the LIG fossil reef localities are presently submerged below modern sea level, and there is an apparent $0.62 \mathrm{~m} / \mathrm{km}$ gradient between LIG deposits from the northwestern and northeastern ends of the island. The authors interpreted this gradient as having resulted from differential subsidence or tilting caused by regional tectonism (Toscano et al., 2012, and references therein). Six corals from this study yielded LIG ages, five from drill cores on Tague Reef on the northeastern end of St. Croix and one from a drill core farther west, on Long Reef. Toscano et al. (2012) accepted all ages except the one from Long Reef (TO12-010). The strict closed-system criteria yielded similar results, but we rejected coral TO12-008 from Tague Reef because of an elevated $\delta^{234} U_{i}$ value. The four corals that passed the strict screening criteria are TO12-005, with an age of $115.1 \pm 0.3 \mathrm{kyr}$; TO12-006, with an age of $124.6 \pm 0.3 \mathrm{kyr}$; TO12-007, with an age of $123.44 \pm 0.4 \mathrm{kyr}$; and TO12-009, with an age of $129.4 \pm 0.4 \mathrm{kyr}$. An additional sample, TO12-008, can also be included under the flexible protocol, yielding an age of $125.7 \pm 0.3 \mathrm{kyr}$.

In Toscano et al. (2012), corals that were not in primary growth position were listed as "fragments". Since none of the corals that passed geochemical screening were stated as being fragments in the Toscano et al. (2012) supplement, we have treated them as being in primary growth position. The authors interpreted the Tague Reef LIG deposit as being part of a reef flat/back-reef setting in $<5 \mathrm{~m}$ water depth, so an interpreted paleowater depth range of $5+0 /-5 \mathrm{~m}$ was adopted. Based on the U-series dating, Toscano et al. (2012) estimated subsidence rates of $0.08 \mathrm{~m} / \mathrm{kyr}$ for Tague Reef and $0.07 \mathrm{~m} / \mathrm{kyr}$ for the Long Reef site.

\subsection{Turks and Caicos}

U-series ages have been reported for 19 corals collected from the LIG Boat Cove and South Reef units on West 
Caicos (Kindler and Meyer, 2012; Kerans et al., 2019). Additional mass spectrometric U-series ages have been reported by Simo et al. (2008), but the type of material dated ranged from "well preserved coral, to skeletal grains and ooids". As Simo et al. (2008) did not specify which carbonate material was dated for each of their ages, their dataset was not included in the present compilation.

Of all the ages reported, a total of 13 were accepted by the study authors. Under both the strict and flexible screening criteria, the two ages from Kindler and Meyer (2012) were rejected due to high calcite content. For the Kerans et al. (2019) study, calcite content was not reported for each sample, but the authors stated that XRD measurements indicated "a range of calcitization $100 \%$ calcite to $3 \%$ calcite", so the authors instead used Sr element mapping to identify the best-preserved sections of coral to date. Based on the range of calcite concentrations given, none of the samples would pass the strict/flexible protocols, so these samples were also rejected.

\subsection{Vanuatu}

Edwards et al. (1987b) reported LIG U-series ages for uplifted coral terraces on Efate Island, Vanuatu. In total, there are three U-series ages for two corals, with one coral (ED87010) measured in duplicate. All three ages were accepted by the study authors and also passed the strict and flexible closed-system criteria. ED87-010 has a weighted mean age of $130.6 \pm 1.1 \mathrm{kyr}$, which constrains the age of the lower Efate terrace, and ED87-011 has an age of $126.5 \pm 1.4 \mathrm{kyr}$, which constrains the age of the upper terrace. No elevation information was reported for these samples, so they cannot be used as RSL indicators. For a regional overview, the reader is directed to Hallman et al. (2020).

\subsection{Western Australia}

Fossil corals from the coastline of Western Australia represent perhaps the broadest geographic region reported here, spanning more than $1400 \mathrm{~km}$ from Cape Range in the north to Foul Bay near the southwestern tip of the Australian continent. It has one of the largest number of U-series ages of any study area covered by WALIS, with 176 U-series ages reported for 156 unique coral specimens (Collins et al., 2003; Eisenhauer et al., 1996; Hearty et al., 2007; O'Leary et al., 2008a, b, 2013; McCulloch and Mortimer, 2008; Stirling et al., 1995, 1998). These sites are considered to be tectonically stable, with one notable exception being sites near the Cape Cuvier anticline, for which there is strong evidence of neotectonism since the LIG (Whitney and Hengesh, 2015).

In the original studies, at least 59 of the U-series ages from 55 coral were accepted. Under the strict screening protocol, the total number of accepted ages dropped substantially to just nine, from five corals, largely because calcite content was not reported in many of the studies. This resulted in $75 \%$ of the dataset being summarily rejected without any assessment of age quality. To remedy this, for the flexible screening protocol, we allowed samples without reported calcite content to be screened using ${ }^{232} \mathrm{Th}$ and $\delta^{234} \mathrm{U}_{\mathrm{i}}$. This is a reasonable judgment call to make, as in previous studies by the same authors only corals with calcite contents below detection limit were dated (e.g., Stirling et al., 1995). Under the flexible screening protocol, we also accepted ZH93-001-001, which had slightly elevated ${ }^{232}$ Th concentration $(\sim 3 \mathrm{ppb})$, and both samples from SI96-002, as they fell along the $129 \mathrm{kyr}$, closed-system isochron. Samples that passed flexible screening were comparable to those that were accepted in the original publications, with 61 ages accepted from 56 unique coral samples. Ages ranged from $116.3 \pm 0.3 \mathrm{kyr}$ (ST98-012) to $134.3 \pm 1.9 \mathrm{kyr}$ for sample EI96-006.

Of the samples that passed the flexible screening protocol, 42 were in primary growth position (45 analyses total) and can be used as RSL indicators. Explicit paleowater depth interpretations were not provided in most cases, so we assigned the modern coral depth distributions for the relevant taxa (OBIS, 2014). It should be noted, however, that many of the samples in the dataset were collected from the very top of the LIG reef outcrops and were likely growing within a few meters of sea level. For samples from Shark Bay (OL08-002, OL08-003, OL08-009, OL08-010), no coral taxonomic information was provided, so these samples should be treated as marine limiting. Additionally, two samples from the Houtman Abrolhos islands (ZH93-001, ZH93-005) were interpreted as being intertidal or subtidal deposits and can be constrained to $<2$ m paleowater depth (Zhu et al., 1993).

\subsection{Yemen}

Fossil coral U-series ages were reported for emergent reef terraces in Yemen, along the Al-Hajaja coast and on Perim Island (Al-Mikhlafi et al., 2018). In total, 35 U-series ages were reported for 33 coral specimens, with two corals dated in duplicate. Al-Mikhlafi et al. (2018) concluded that terrace $\operatorname{Tr} 3$ from the study area was LIG in age but decided against using any of the samples collected as RSL indicators, as most of the corals were diagenetically altered. None of the U-series ages from Yemen met the strict or flexible closed-system criteria.

\subsection{Yucatán, Mexico}

Two reef tracts were uncovered during the excavation and construction of the Xcaret theme park near Playa del Carmen, Mexico (see Simms, 2021, for a regional overview). Useries ages are available from both reef tracts, which included Acropora palmata and Siderastrea siderea corals (Blanchon et al., 2009). In total, 33 U-series ages were reported from 10 unique coral specimens, with each coral dated at least in triplicate. In total, the study authors accepted seven analyses from five corals. Both the strict and flexible screening criteria rejected all but three analyses, primarily because multi- 
ple subsamples that were dated for the rejected coral specimens did not yield reproducible $\mathrm{U}$-series ages. The three ages that passed screening were both from upper reef tract sample BL09-006, giving a weighted mean age of $123.9 \pm 0.7 \mathrm{kyr}$. This sample, however, was identified as a clast by Blanchon et al. (2009) and therefore cannot be used as an RSL indicator.

\section{Further details}

\subsection{Other interglacials}

Multiple studies published coral U-series ages $>150 \mathrm{kyr}$, suggesting the corals grew during previous glacialinterglacial cycles (e.g., Andersen et al., 2008, 2010b; Bard et al., 1991; Camoin et al., 2001; Gallup et al., 1994; Hearty et al., 1999; Kennedy et al., 2012; McMurtry et al., 2010; Muhs et al., 2011; Stirling et al., 2001; Thomas et al., 2012; Vezina et al., 1999; Zazo et al., 2007). Assessing the quality of pre-LIG fossil coral U-series ages would require opensystem modeling, which is beyond the scope of this study.

\subsection{Holocene coral data}

Holocene coral U-series ages are not included in this study. These data are, however, being compiled by the HOLSEA working group (Khan et al., 2019; https://www.holsea.org, last access: 28 June 2021).

\subsection{Controversies}

One of the outstanding controversies for fossil coral RSL reconstructions is whether fossil reef sites record evidence of millennial- or centennial-scale sea-level change within the LIG. Constraining the anatomy (pattern) of GMSL change within the LIG is crucial for our understanding of ice sheet dynamics in warm interglacial periods, such as today, and has direct bearing on future projections of sea-level response to anthropogenic forcing (Church et al., 2013; DeConto and Pollard, 2016; Sweet et al., 2017). The analytical precision of U-series dating and field surveying techniques has advanced dramatically over the past 30 years, but this key question remains unresolved (Kopp et al., 2017).

\section{Data availability}

The current version of the dataset can be accessed using the following link: https://doi.org/10.5281/zenodo.4309796 (Chutcharavan and Dutton, 2020). The descriptions of the different database fields can be found here: https://doi.org/10.5281/zenodo.3961543 (Rovere et al., 2020). The version of the coral U-series dataset referenced in this paper is included in Supplement S1.

\section{Future research directions}

Reconciling different interpretations of GMSL pathways during the LIG will require an approach that integrates age, elevation and sedimentary/facies evidence at key fossil reef sites. At the site/regional level, precise U-series age constraints are needed for key LIG fossil reef sites and must be combined with a rigorous assessment of diagenesis and its effect on U-series age quality (Dechnik et al., 2017; Dutton et al., 2015b; Obert et al., 2016; Tomiak et al., 2016). Our understanding of LIG sea-level change will be further advanced if efforts are made to better integrate U-series age information within the context of coral elevation and existing site metadata (e.g., facies analysis, paleoecological interpretations). Moving forward, there are several "best practices" that can further this goal, including the following:

1. During field collection, the vertical position and depositional context should be thoroughly documented, including an assessment of whether the sampled coral is in primary growth position.

2. Whenever possible, multiple subsamples of an LIG fossil coral should be dated to screen for open-system behavior and verify age reproducibility.

3. Finally, U-series ages that are accepted should be evaluated in the context of existing facies and paleoecological interpretations for the study site, to quantify the paleowater depth uncertainty for each fossil coral RSL data point.

These interpretations are needed to ensure that U-seriesdated fossil corals continue to provide robust RSL information that can answer important questions about LIG sea level.

Supplement. The supplement related to this article is available online at: https://doi.org/10.5194/essd-13-3155-2021-supplement.

Author contributions. PMC compiled the coral U-series database, developed the closed-system screening protocols and wrote the paper with assistance and guidance from AD. PMC and AD designed the U-series database structure.

Competing interests. The authors declare that they have no conflict of interest.

Disclaimer. Publisher's note: Copernicus Publications remains neutral with regard to jurisdictional claims in published maps and institutional affiliations. 
Special issue statement. This article is part of the special issue "WALIS - the World Atlas of Last Interglacial Shorelines". It is not associated with a conference.

Acknowledgements. This database was compiled in WALIS, a sea-level database interface developed by the ERC Starting Grant "WARMCOASTS" (ERC-StG-802414), in collaboration with the PALSEA (PAGES/INQUA) working group. The database structure was designed by Alessio Rovere, Deirdre Ryan, Thomas Lorscheid, Andrea Dutton, Peter Chutcharavan, Dominik Brill, Nathan Jankowski, Daniela Mueller, Melanie Bartz, Evan Gowan and Kim Cohen. We thank Barbara Mauz as well as two anonymous referees for the helpful feedback they provided during the open discussion period, as well as Alessio Rovere for his assistance in designing and implementing the U-series and fossil coral RSL components of the WALIS interface and Karla Rubio Sandoval who helped compile data for the portions of the Curaçao fossil reef sites.

Financial support. This research has been supported by the National Science Foundation (grant nos. 1702740 and 1443037).

Review statement. This paper was edited by Alessio Rovere and reviewed by two anonymous referees.

\section{References}

Abbey, E., Webster, J. M., Braga, J.-C., Sugihara, K., Wallace, C., Iryu, Y., Potts, D., Done, T., Camoin, G., and Seard, C.: Variation in deglacial coralgal assemblages and their paleoenvironmental significance: IODP Expedition 310, "Tahiti Sea Level," Global Planet. Change, 76, 1-15, https://doi.org/10.1016/j.gloplacha.2010.11.005, 2011.

Al-Mikhlafi, A. S., Edwards, L. R., and Cheng, H.: Sea-level history and tectonic uplift during the last-interglacial period (LIG): Inferred from the Bab al-Mandab coral reef terraces, southern Red Sea, J. African Earth Sci., 138, 133-148, https://doi.org/10.1016/j.jafrearsci.2017.10.023, 2018.

Andersen, M. B., Stirling, C. H., Potter, E. K., Halliday, A. N., Blake, S. G., McCulloch, M. T., Ayling, B. F., and O'Leary, M. J.: High-precision U-series measurements of more than 500,000 year old fossil corals, Earth Planet. Sc. Lett., 265, 229-245, https://doi.org/10.1016/j.epsl.2007.10.010, 2008.

Andersen, M. B., Stirling, C. H., Zimmermann, B., and Halliday, A. N.: Precise determination of the open ocean ${ }^{234} \mathrm{U} /{ }^{238} \mathrm{U}$ composition, Geochem. Geophy. Geosy., 11, 12, https://doi.org/10.1029/2010GC003318, 2010a.

Andersen, M. B., Stirling, C. H., Potter, E. K., Halliday, A. N., Blake, S. G., McCulloch, M. T., Ayling, B. F., and O'Leary, M. J.: The timing of sea-level high-stands during Marine Isotope Stages 7.5 and 9: Constraints from the uranium-series dating of fossil corals from Henderson Island, Geochim. Cosmochim. Ac., 74, 3598-3620, https://doi.org/10.1016/j.gca.2010.03.020, 2010b.

Austermann, J., Mitrovica, J. X., Huybers, P., and Rovere, A.: Detection of a dynamic topography signal in last interglacial sea level records, Sci. Adv., 3, 1-8, https://doi.org/10.1126/sciadv.1700457, 2017.

Bar, N., Agnon, A., Yehudai, M., Lazar, B., Shaked, Y., and Stein, M.: Last interglacial sea levels and regional tectonics from fossil coral reefs in the northeast Gulf of Aqaba, Quaternay Sci. Rev., 191, 41-56, https://doi.org/10.1016/j.quascirev.2018.04.031, 2018.

Bard, E., Hamelin, B., Fairbanks, R. G., and Zindler, A.: Calibration of the $\mathrm{C}$-14 timescale over the past 30,000 years using mass spectrometric U-Th ages from Barbados corals, Nature, 345, 405410, https://doi.org/10.1038/345405a0, 1990.

Bard, E., Fairbanks, R. G., Hamelin, B., Zindler, A., and Hoang, C. T.: Uranium-234 anomalies in corals older than 150,000 years, Geochim. Cosmochim. Ac., 55, 2385-2390, https://doi.org/10.1016/0016-7037(91)90115-L, 1991.

Bard, E., Jouannic, C., Hamelin, B., Pirazzoli, P., Arnold, M., Faure, G., Sumosusastro, P., and Syaefudin: Pleistocene sea levels and tectonic uplift based on dating of corals from Sumba Island, Indonesia, Geophys. Res. Lett., 23, 1473, https://doi.org/10.1029/96GL01279, 1996.

Bender, M. L., Fairbanks, R. G., Taylor, F. W., Matthews, R. K., Goddard, J. G., and Broecker, W. S.: Uranium-series dating of the Pleistocene reef tracts of Barbados, West Indies, Bull. Geol. Soc. Am., 90, 577-594, https://doi.org/10.1130/00167606(1979)90<577:UDOTPR>2.0.CO;2, 1979.

Blanchon, P. and Eisenhauer, A.: Multi-stage reef development on Barbados during the Last Interglaciation, Quaternary Sci. Rev., 20, 1093-1112, https://doi.org/10.1016/S0277-3791(00)001736, 2001 .

Blanchon, P., Eisenhauer, A., Fietzke, J., and Liebetrau, V.: Rapid sea-level rise and reef back-stepping at the close of the last interglacial highstand - Supplement, Nature, 458, 881-884, https://doi.org/10.1038/nature07933, 2009.

Boyden, P., Weil-Accardo, J., Deschamps, P., Oppo, D., and Rovere, A.: Last interglacial sea-level proxies in East Africa and the Western Indian Ocean, Earth Syst. Sci. Data, 13, 1633-1651, https://doi.org/10.5194/essd-13-1633-2021, 2021.

Braithwaite, C. J. R., Dalmasso, H., Gilmour, M. A., Harkness, D. D., Henderson, G. M., Kay, R. L. F., Kroon, D., Montaggioni, L. F., and Wilson, P. A.: The Great Barrier Reef: the chronological record from a new borehole, J. Sediment. Res., 74, 298-310, 2004.

Broecker, W. S., Thurber, D. L., Goddard, J., Ku, T. L., Matthews, R. K., and Mesolella, K. J.: Milankovitch hypothesis supported by precise dating of coral reefs and deep-sea sediments, Science, 159, 297-300, https://doi.org/10.1126/science.159.3812.297, 1968.

Cabioch, G., Montaggioni, L. F., Faure, G., and Ribaud-Laurenti, A.: Reef coralgal assemblages as recorders of paleobathymetry and sea level changes in the Indo-Pacific province, Quaternary Sci. Rev., 18, 1681-1695, https://doi.org/10.1016/S02773791(99)00014-1, 1999.

Camoin, G. F., Ebren, P., Eisenhauer, A., Bard, E., and Faure, G.: A $300000-y r$ coral reef record of sea level changes, Mururoa atoll (Tuamotu archipelago, French Polynesia), Palaeogeogr. Palaeoclim., 175, 325-341, https://doi.org/10.1016/S00310182(01)00378-9, 2001. 
Chen, J. H., Lawrence Edwards, R., and Wasserburg, G. J.: ${ }^{238} \mathrm{U}$, ${ }^{234} \mathrm{U}$ and ${ }^{232} \mathrm{Th}$ in seawater, Earth Planet. Sc. Lett., 80, 241-251, https://doi.org/10.1016/0012-821X(86)90108-1, 1986.

Chen, J. H., Curran, H. A., White, B., and Wasserburg, G. J.: Precise chronology of the last interglacial period: ${ }^{234} \mathrm{U}^{230} \mathrm{Th}$ data from fossil coral, Geol. Soc. Am. Bull., 103, 82-97, https://doi.org/10.1130/00167606(1991)103<0082:PCOTLI>2.3.CO;2, 1991.

Chen, T., Chen, T., Robinson, L. F., Beasley, M. P., Claxton, L. M., Andersen, M. B., Lauren, J., Wadham, J., Fornari, D. J., and Harpp, K. S.: Ocean mixing and ice-sheet control of seawater ${ }^{234} U /{ }^{238} \mathrm{U}$ during the last deglaciation, Science, 1015, 626-629, https://doi.org/10.1126/science.aag1015, 2016.

Cheng, H., Edwards, R. L., Hoff, J., Gallup, C. D., Richards, D. A., and Asmerom, Y.: The half-lives of uranium-234 and thorium230, Chem. Geol., 169, 17-33, https://doi.org/10.1016/S00092541(99)00157-6, 2000.

Cheng, H., Lawrence Edwards, R., Shen, C. C., Polyak, V. J., Asmerom, Y., Woodhead, J., Hellstrom, J., Wang, Y., Kong, X., Spötl, C., Wang, X., and Calvin Alexander, E.: Improvements in ${ }^{230} \mathrm{Th}$ dating, ${ }^{230} \mathrm{Th}$ and ${ }^{234} \mathrm{U}$ half-life values, and $\mathrm{U}-\mathrm{Th}$ isotopic measurements by multi-collector inductively coupled plasma mass spectrometry, Earth Planet. Sc. Lett., 371-372, 8291, https://doi.org/10.1016/j.eps1.2013.04.006, 2013.

Church, J. A., Clark, P. U., Cazenave, A., Gregory, J. M., Jevrejeva, S., Levermann, A., Merrifield, M. A., Milne, G. A., Nerem, R. S., Nunn, P. D., Payne, A. J., Pfeffer, W. T., Stammer, D., and Unnikrishnan, A. S.: Sea level Change, Climate Change 2013, The Physical Science Basis, Contribution of Working Group I to the Fifth Assessment Report of the Intergovernmental Panel on Climate Change, 1137-1216, 2013.

Chutcharavan, P. M. and Dutton, A.: Global database of U-series dated fossil coral sea-level indicators for the Last Interglacial period, Zenodo, https://doi.org/10.5281/zenodo.4309796, 2020.

Chutcharavan, P. M., Dutton, A., and Ellwood, M. J.: Seawater ${ }^{234} \mathrm{U} /{ }^{238} \mathrm{U}$ recorded by modern and fossil corals, Geochim. Cosmochim. Ac., 224, 1-17, https://doi.org/10.1016/j.gca.2017.12.017, 2018.

Clark, P. U., He, F., Golledge, N. R., Mitrovica, J. X., Dutton, A., Hoffman, J. S., and Dendy, S.: Oceanic forcing of penultimate deglacial and last interglacial sea-level rise, Nature, 577, 660664, https://doi.org/10.1038/s41586-020-1931-7, 2020.

Cobb, K. M., Charles, C. D., Cheng, H., Kastner, M., and Edwards, R. L.: U/Th-dating living and young fossil corals from the central tropical Pacific, Earth Planet. Sc. Lett., 210, 91-103, https://doi.org/10.1016/S0012-821X(03)00138-9, 2003.

Collins, L. B., Zhu, Z. R., Wyrwoll, K.-H., and Eisenhauer, A.: Late Quaternary structure and development of the northern Ningaloo Reef, Australia, Sediment. Geol., 159, 81-94, https://doi.org/10.1016/S0037-0738(03)00096-4, 2003.

Coyne, M. K., Jones, B., and Ford, D.: Highstands during Marine Isotope Stage 5: evidence from the Ironshore Formation of Grand Cayman, British West Indies, Quaternary Sci. Rev., 26, 536-559, https://doi.org/10.1016/j.quascirev.2006.06.013, 2007.

Creveling, J. R., Mitrovica, J. X., Hay, C. C., Austermann, J., and Kopp, R. E.: Revisiting tectonic corrections applied to Pleistocene sea-level highstands, Quaternary Sci. Rev., 111, 72-80, https://doi.org/10.1016/j.quascirev.2015.01.003, 2015.
Cutler, K. B., Edwards, R. L., Taylor, F. W., Cheng, H., Adkins, J. F., Gallup, C. D., Cutler, P. M., Burr, G. S., and Bloom, A. L.: Rapid sea-level fall and deep-ocean temperature change since the last interglacial period, Earth Planet. Sc. Lett., 206, 253-271, https://doi.org/10.1016/S0012-821X(02)01107-X, 2003.

Dechnik, B., Webster, J. M., Webb, G. E., Nothdurft, L., Dutton, A., Braga, J., Zhao, J., Duce, S., and Sadler, J.: The evolution of the Great Barrier Reef during the Last Interglacial Period, Glob. Planet. Change, 149, 53-71, https://doi.org/10.1016/j.gloplacha.2016.11.018, 2017.

DeConto, R. M. and Pollard, D.: Contribution of Antarctica to past and future sea-level rise, Nature, 531, 591-597, https://doi.org/10.1038/nature17145, 2016.

Dendy, S., Austermann, J., Creveling, J. R., and Mitrovica, J. X.: Sensitivity of Last Interglacial sea-level high stands to ice sheet configuration during Marine Isotope Stage 6, Quaternary Sci. Rev., 171, 234-244, https://doi.org/10.1016/j.quascirev.2017.06.013, 2017.

Dia, A. N., Cohen, A. S., O'Nions, R. K., and Jackson, J. A.: Rates of uplift investigated through ${ }^{230} \mathrm{Th}$ dating in gulf of Corinth (Greece), Chem. Geol., 171-184, 1997.

Dodge, R. E., Fairbanks, R. G., Benninger, L. K., and Maurrasse, F.: Pleistocene Sea Levels from Raised Coral Reefs of Haiti, Science, 219, 1423-1425, 1983.

Dutton, A. and Lambeck, K.: Ice Volume and Sea Level During the Last Interglacial, Science, 337, 216-219, https://doi.org/10.1126/science.1205749, 2012.

Dutton, A., Carlson, A. E., Long, A. J., Milne, G. A., Clark, P. U., DeConto, R., Horton, B. P., Rahmstorf, S., and Raymo, M. E.: Sea-level rise due to polar ice-sheet mass loss during past warm periods, Science, 349, 6244, https://doi.org/10.1126/science.aaa4019, 2015a.

Dutton, A., Webster, J. M., Zwartz, D., Lambeck, K., and Wohlfarth, B.: Tropical tales of polar ice: evidence of Last Interglacial polar ice sheet retreat recorded by fossil reefs of the granitic Seychelles islands, Quaternary Sci. Rev., 107, 182-196, https://doi.org/10.1016/j.quascirev.2014.10.025, 2015 b.

Dutton, A., Rubin, K., Mclean, N., Bowring, J., Bard, E., Edwards, R. L., Henderson, G. M., Reid, M. R., Richards, D. A., Sims, K. W. W., Walker, J. D., and Yokoyama, Y.: Data reporting standards for publication of U-series data for geochronology and timescale assessment in the earth sciences, Quat. Geochronol., 39, 142149, https://doi.org/10.1016/j.quageo.2017.03.001, 2017.

Edwards, R. L., Chen, J. H., and Wasserburg, G. J.: ${ }^{238}{ }^{\mathrm{U}}{ }^{234} \mathrm{U}-$ ${ }^{230} \mathrm{Th}-{ }^{232} \mathrm{Th}$ systematics and the precise measurement of time over the past 500,000 years, Earth Planet. Sc. Lett., 81, 175-192, https://doi.org/10.1016/0012-821X(87)90154-3, 1987a.

Edwards, R. L., Chen, J. H., Ku, T. L., and Wasserburg, G. J.: Precise timing of the last interglacial period from mass spectrometric determination of thorium-230 in corals, Science, 236, 15471553, https://doi.org/10.1126/science.236.4808.1547, $1987 \mathrm{~b}$.

Edwards, R. L., Cheng, H., Murrell, M. T., and Goldstein, S. J.: Protactinium-231 Dating of Carbonates by Thermal Ionization Mass Spectrometry: Implications for Quaternary Climate Change, Science, 276, 782-786, https://doi.org/10.1126/science.276.5313.782, 1997.

Edwards, R. L., Gallup, C. D., and Cheng, H.: Uranium-series Dating of Marine and Lacustrine Carbonates, Rev. Mineral. Geochem., 52, 363-405, https://doi.org/10.2113/0520363, 2003. 
Eisenhauer, A., Zhu, Z. R., Collins, L. B., Wyrwoll, K.-H., and Eichstätter, R.: The Last Interglacial sea level change: new evidence from the Abrolhos islands, West Australia, Geol. Rundschau, 85, 606-614, https://doi.org/10.1007/BF02369014, 1996.

Esat, T. M., McCulloch, M. T., Chappell, J., Pillans, B., and Omura, A.: Rapid Fluctuations in Sea Level Recorded at Huon Peninsula During the Penultimate Deglaciation, Science, 283, 197201, https://doi.org/10.1126/science.283.5399.197, 1999.

Farrell, W. E. and Clark, J. A.: On Postglacial Sea Level, Geophys. J. R. Astron. Soc., 46, 647-667, https://doi.org/10.1111/j.1365246X.1976.tb01252.x, 1976.

Frank, N., Turpin, L., Cabioch, G., Blamart, D., Tressens-Fedou, M., Colin, C., and Jean-Baptiste, P.: Open system U-series ages of corals from a subsiding reef in New Caledonia: Implications for sea level changes, and subsidence rate, Earth Planet. Sc. Lett., 249, 274-289, https://doi.org/10.1016/j.eps1.2006.07.029, 2006.

Fruijtier, C., Elliott, T., and Schlager, W.: Mass-spectrometric ${ }^{234} \mathrm{U}-{ }^{230}$ Th ages from the Key Largo Formation, Florida Keys, United States: Constraints on diagenetic age disturbance, GSA Bulletin, 112, 267-277, https://doi.org/10.1130/00167606(2000)112<267:MUAFTK>2.0.CO;2, 2000.

Gallup, C. D., Edwards, R. L., and Johnson, R. G.: The timing of high sea levels over the past 200,000 years, Science, 263, 796800, https://doi.org/10.1126/science.263.5148.796, 1994.

Gallup, C. D., Cheng, H., Taylor, F. W., and Edwards, R. L.: Direct determination of the timing of sea level change during termination II, Science, 295, 310-313, https://doi.org/10.1126/science.1065494, 2002.

Hallmann, N., Camoin, G., Webster, J. M., and Humblet, M.: A standardized database of Marine Isotopic Stage 5e sea-level proxies on tropical Pacific Islands, Earth Syst. Sci. Data Discuss. [preprint], https://doi.org/10.5194/essd-2020-261, in review, 2020.

Hamelin, B., Bard, E., Zindler, A., and Fairbanks, R. G.: ${ }^{234} \mathrm{U} /{ }^{238} \mathrm{U}$ mass spectrometry of corals: How accurate is the UTh age of the last interglacial period?, Earth Planet. Sc. Lett., 106, 169-180, https://doi.org/10.1016/0012-821X(91)90070-X, 1991.

Hay, C., Mitrovica, J. X., Gomez, N., Creveling, J. R., Austermann, J., and E. Kopp, R.: The sea-level fingerprints of ice-sheet collapse during interglacial periods, Quaternary Sci. Rev., 87, 6069, https://doi.org/10.1016/j.quascirev.2013.12.022, 2014.

Hearty, P. J., Kindler, P., Cheng, H., and Edwards, R. L.: A $+20 \mathrm{~m}$ middle Pleistocene sea-level highstand (Bermuda and the Bahamas) due to partial collapse of Antarctic ice, Geology, 27, 375-378, https://doi.org/10.1130/00917613(1999)027<0375:AMMPSL>2.3.CO;2, 1999.

Hearty, P. J., Hollin, J. T., Neumann, A. C., O'Leary, M. J., and McCulloch, M. T.: Global sea-level fluctuations during the Last Interglaciation (MIS 5e), Quaternary Sci. Rev., 26, 2090-2112, https://doi.org/10.1016/j.quascirev.2007.06.019, 2007.

Henderson, G. M. and Slowey, N. C.: Evidence from U-Th dating against Northern Hemisphere forcing of the penultimate deglaciation, Nature, 404, 61-66, https://doi.org/10.1038/35003541, 2000.

Hibbert, F. D., Rohling, E. J., Dutton, A., Williams, F. H., Chutcharavan, P. M., Zhao, C., and Tamisiea, M. E.: Coral indicators of past sea-level change: A global repository of U-series dated benchmarks, Quaternary Sci. Rev., 145, 1-56, https://doi.org/10.1016/j.quascirev.2016.04.019, 2016.
Israelson, C. and Wohlfarth, B.: Timing of the Last-Interglacial High Sea Level on the Seychelles Islands, Indian Ocean, Quaternary Res., 51, 306-316, https://doi.org/10.1006/qres.1998.2030, 1999.

Kennedy, D. M., Marsters, T. H., Woods, J. L. D., and Woodroffe, C. D.: Shore platform development on an uplifting limestone island over multiple sea-level cycles, Niue, South Pacific, Geomorphology, 141-142, 170-182, https://doi.org/10.1016/j.geomorph.2011.12.041, 2012.

Kerans, C., Zahm, C., Bachtel, S. L., Hearty, P., and Cheng, H.: Anatomy of a late Quaternary carbonate island: Constraints on timing and magnitude of sea-level fluctuations, West Caicos, Turks and Caicos Islands, BWI, Quaternary Sci. Rev., 205, 193223, https://doi.org/10.1016/j.quascirev.2018.12.010, 2019.

Khan, N. S., Horton, B. P., Engelhart, S., Rovere, A., Vacchi, M., Ashe, E. L., Törnqvist, T. E., Dutton, A., Hijma, M. P., and Shennan, I.: Inception of a global atlas of sea levels since the Last Glacial Maximum, Quaternary Sci. Rev., 220, 359-371, https://doi.org/10.1016/j.quascirev.2019.07.016, 2019.

Kindler, P. and Meyer, A.: New U/Th and amino-acid racemization dating and interpretation of Pleistocene sequences from West Caicos Island (Caicos platform): Implication for cyclostratigraphy, Symp. Geol. Bahamas other Carbonate Reg., 15, 82-95, available at: http://archive-ouverte.unige.ch/unige:45601 (last access: 9 December 2020), 2012.

Kopp, R. E., Simons, F. J., Mitrovica, J. X., Maloof, A. C., and Oppenheimer, M.: Probabilistic assessment of sea level during the last interglacial stage, Nature, 462, 863-867, https://doi.org/10.1038/nature08686, 2009.

Kopp, R. E., Dutton, A., and Carlson, A.: Centennial- to millennialscale sea-level change during the Holocene and Last Interglacial periods, Past Glob. Chang. Mag., 25, 148-149, https://doi.org/10.22498/pages.25.3.148, 2017.

Le Roy, I.: Evolution des volcans en système de point chaud: Ile de Tahiti, archipel de la Société (Polynésie Française), Doctoral dissertation, Université de Paris XI, 1994.

Lighty, R., Macintyre, I., and Stuckenrath, R.: Acropora Palmata Reef Framework: A Reliable Indicator of Sea Level in the Western Atlantic for the Past 10,000 Years, Coral Reefs, 1, 125-130, 1982.

Lorscheid, T. and Rovere, A.: The indicative meaning calculator - quantification of paleo sea-level relationships by using global wave and tide datasets, Open Geospatial Data, Softw. Stand., 4, 10, https://doi.org/10.1186/s40965-019-0069-8, 2019.

Ludwig, K. R., Muhs, D. R., Simmons, K. R., Halley, R. B., and Shinn, E. A.: Sea-level records at $\sim 80 \mathrm{ka}$ from tectonically stable platforms: Florida and Bermuda, Geology, 24, 211-214, https://doi.org/10.1130/00917613(1996)024<0211:SLRAKF>2.3.CO;2, 1996.

Manaa, A. A., Jones, B. G., McGregor, H. V., Zhao, J. X., and Price, D. M.: Dating Quaternary raised coral terraces along the Saudi Arabian Red Sea coast, Mar. Geol., 374, 59-72, https://doi.org/10.1016/j.margeo.2016.02.002, 2016.

Masson-Delmotte, V., Schulz, M., Abe-Ouchi, A., Beer, J., Ganopolski, A., González Rouco, J. F., Jansen, E., Lambeck, K., Luterbacher, J., Naish, T., Osborn, T., Otto-Bliesner, B., Quinn, T., Ramesh, R., Rojas, M., Shao, X., and Timmermann, A: Information from paleoclimate archives, in: Climate Change 2013: the Physical Science Basis. Contribution of Working Group I to the 
Fifth Assessment Report of the Intergovernmental Panel on Climate Change, edited by: Stocker, T. F., Qin, D., Plattner, G. K., Tignor, M., Allen, S. K., Boschung, J., Nauels, A., Xia, Y., Bex, V., and Midgley, P. M., Cambridge University Press, Cambridge, United Kingdom and New York, NY, USA, 2013.

Maxwell, K., Westphal, H., and Rovere, A.: A standardized database of Last interglacial (MIS 5e) sea-level indicators in Southeast Asia, Earth Syst. Sci. Data Discuss. [preprint], https://doi.org/10.5194/essd-2021-126, in review, 2021.

McCulloch, M. T. and Mortimer, G. E.: Th decay series to dating of fossil and modern corals using MC-ICPMS, Aust. J. Earth Sci., 55, 955-965, https://doi.org/10.1080/08120090802097435, 2008.

McMurtry, G. M., Campbell, J. F., Fryer, G. J., and Fietzke, J.: Uplift of Oahu, Hawaii, during the past 500 k.y. as recorded by elevated reef deposits, Geology, 38, 27-30, https://doi.org/10.1130/G30378.1, 2010.

Medina-Elizalde, M.: A global compilation of coral sea-level benchmarks: Implications and new challenges, Earth Planet. Sc. Lett., 362, 310-318, https://doi.org/10.1016/j.eps1.2012.12.001, 2013.

Mitrovica, J. X. and Milne, G. A.: On post-glacial sea level: I. General theory, Geophys. J. Int., 152, 253-267, 2003.

Montaggioni, L. F. and Hoang, C. T.: The last interglacial high sea level in the granitic Seychelles, Indian ocean, Palaeogeogr. Palaeoclimatol. Palaeoecol., 64(1-2), 79-91, https://doi.org/10.1016/0031-0182(88)90144-7, 1988.

Moucha, R., Forte, A. M., Mitrovica, J. X., Rowley, D. B., Quéré, S., Simmons, N. A., and Grand, S. P.: Dynamic topography and long-term sea-level variations: There is no such thing as a stable continental platform, Earth Planet. Sc. Lett., 271, 101-108, https://doi.org/10.1016/j.epsl.2008.03.056, 2008.

Muhs, D. R. and Simmons, K. R.: Taphonomic problems in reconstructing sea-level history from the late Quaternary marine terraces of Barbados, Quaternary Res., 88, 409-429, https://doi.org/10.1017/qua.2017.70, 2017.

Muhs, D. R., Simmons, K. R., Kennedy, G. L., and Rockwell, T. K.: The last interglacial period on the pacific coast of north america:timing and paleoclimate, GSA Bulletin, 114, 569-592, https://doi.org/10.1130/00167606(2002)114<0569:TLIPOT>2.0.CO;2, 2002a.

Muhs, D. R., Simmons, K. R., and Steinke, B.: Timing and warmth of the Last Interglacial period: New U-series evidence from Hawaii and Bermuda and a new fossil compilation for North America, Quaternary Sci. Rev., 21, 1355-1383, https://doi.org/10.1016/S0277-3791(01)00114-7, 2002b.

Muhs, D. R., Simmons, K. R., Kennedy, G. L., Ludwig, K. R., and Groves, L. T.: A cool eastern Pacific Ocean at the close of the Last Interglacial complex, Quaternary Sci. Rev., 25, 235-262, https://doi.org/10.1016/j.quascirev.2005.03.014, 2006.

Muhs, D. R., Simmons, K. R., Schumann, R. R., and Halley, R. B.: Sea-level history of the past two interglacial periods: New evidence from U-series dating of reef corals from south Florida, Quaternary Sci. Rev., 30, 570-590, https://doi.org/10.1016/j.quascirev.2010.12.019, 2011.

Muhs, D. R., Simmons, K. R., Schumann, R. R., Groves, L. T., Mitrovica, J. X., and Laurel, D.: Sea-level history during the Last Interglacial complex on San Nicolas Island, California: Implications for glacial isostatic adjustment processes, paleo- zoogeography and tectonics, Quaternary Sci. Rev., 37, 1-25, https://doi.org/10.1016/j.quascirev.2012.01.010, 2012a.

Muhs, D. R., Pandolfi, J. M., Simmons, K. R., and Schumann, R. R.: Sea-level history of past interglacial periods from uranium-series dating of corals, Curaçao, Leeward Antilles islands, Quaternary Res., 78, 157-169, https://doi.org/10.1016/j.yqres.2012.05.008, 2012b.

Muhs, D. R., Meco, J., and Simmons, K. R.: Uranium-series ages of corals, sea level history, and palaeozoogeography, Canary Islands, Spain: An exploratory study for two Quaternary interglacial periods, Palaeogeogr. Palaeoclim., 394, 99-118, https://doi.org/10.1016/j.palaeo.2013.11.015, 2014.

Müller, R. D., Sdrolias, M., Gaina, C., Steinberger, B., and Heine, C.: Long-Term Sea-Level Fluctuations, Science, 319, 13571363, https://doi.org/10.1126/science.1151540, 2008.

Multer, H. G., Gischler, E., Lundberg, J., Simmons, K. R., and Shinn, E. A.: Key Largo Limestone revisited: Pleistocene shelf-edge facies, Florida Keys, USA, Facies, 46, 229-271, https://doi.org/10.1007/BF02668083, 2002.

O'Leary, M. J., Hearty, P. J., and McCulloch, M. T.: Geomorphic evidence of major sea-level fluctuations during marine isotope substage-5e, Cape Cuvier, Western Australia, Geomorphology, 102, 595-602, https://doi.org/10.1016/j.geomorph.2008.06.004, 2008a.

O'Leary, M. J., Hearty, P. J., and McCulloch, M. T.: U-series evidence for widespread reef development in Shark Bay during the last interglacial, Palaeogeogr. Palaeoclim., 259, 424-435, https://doi.org/10.1016/j.palaeo.2007.10.022, 2008b.

O'Leary, M. J., Hearty, P. J., Thompson, W. G., Raymo, M. E., Mitrovica, J. X., and Webster, J. M.: Ice sheet collapse following a prolonged period of stable sea level during the last interglacial, Nat. Geosci., 6, 796-800, https://doi.org/10.1038/ngeo1890, 2013.

Obert, J. C., Scholz, D., Felis, T., Brocas, W. M., Jochum, K. P., and Andreae, M. O.: ${ }^{230} \mathrm{Th} / \mathrm{U}$ dating of Last Interglacial brain corals from Bonaire (southern Caribbean) using bulk and theca wall material, Geochim. Cosmochim. Ac., 178, 20-40, https://doi.org/10.1016/j.gca.2016.01.011, 2016.

OBIS: Data from the Ocean Biogeographic Information System, Intergovernmental Oceanographic Commission of UNESCO. Web., available at: http://www.iobis.org, last access: 21 March 2014.

Pan, T., Murray-wallace, C. V., Dosseto, A., and Bourman, R. P.: The last interglacial (MIS 5e) sea level highstand from a tectonically stable far-field setting, Yorke Peninsula, southern Australia, Mar. Geol., 398, 126-136, https://doi.org/10.1016/j.margeo.2018.01.012, 2018.

Pedoja, K., Husson, L., Bezos, A., Pastier, A. M., Imran, A. M., Arias-Ruiz, C., Sarr, A. C., Elliot, M., Pons-Branchu, E., Nexer, M., Regard, V., Hafidz, A., Robert, X., Benoit, L., Delcaillau, B., Authemayou, C., Dumoulin, C., and Choblet, G.: On the long-lasting sequences of coral reef terraces from SE Sulawesi (Indonesia): Distribution, formation, and global significance, Quaternary Sci. Rev., 188, 37-57, https://doi.org/10.1016/j.quascirev.2018.03.033, 2018.

Perkins, R. D.: Part II: Depositional framework of Pleistocene rocks in south Florida, Mem. Geol. Soc. Am., 147, 131-198, https://doi.org/10.1130/MEM147-p131, 1977. 
Rovere, A., Raymo, M. E., Vacchi, M., Lorscheid, T., Stocchi, P., Gómez-Pujol, L., Harris, D. L., Casella, E., O’Leary, M. J., and Hearty, P. J.: The analysis of Last Interglacial (MIS 5e) relative sea-level indicators: Reconstructing sealevel in a warmer world, Earth-Sci. Rev., 159, 404-427, https://doi.org/10.1016/j.earscirev.2016.06.006, 2016.

Rovere, A., Ryan, D., Murray-Wallace, C., Simms, A., Vacchi, M., Dutton, A., Lorscheid, T., Chutcharavan, P., Brill, D., Bartz, M., Jankowski, N., Mueller, D., Cohen, K., and Gowan, E.: Descriptions of database fields for the World Atlas of Last Interglacial Shorelines (WALIS), Zenodo, https://doi.org/10.5281/zenodo.3961543, 2020.

Rowley, D. B., Forte, A. M., Moucha, R., Mitrovica, J. X., Simmons, N. A., and Grand, S. P.: Dynamic topography change of the eastern United States since 3 million years ago, Science, 340, 1560-1563, https://doi.org/10.1126/science.1229180, 2013.

Rubio-Sandoval, K., Rovere, A., Cerrone, C., Stocchi, P., Lorscheid, T., Felis, T., Petersen, A.-K., and Ryan, D. D.: A review of Last Interglacial sea-level proxies in the Western Atlantic and Southwestern Caribbean, from Brazil to Honduras, Earth Syst. Sci. Data Discuss. [preprint], https://doi.org/10.5194/essd-2021-150, in review, 2021.

Scholz, D. and Mangini, A.: How precise are U-series coral ages?, Geochim. Cosmochim. Ac., 71, 1935-1948, https://doi.org/10.1016/j.gca.2007.01.016, 2007.

Scholz, D., Mangini, A., and Meischner, D.: 9. U-redistribution in fossil reef corals from Barbados, West Indies, and sealevel reconstruction for MIS 6.5, Dev. Quat. Sci., 7, 119-139, https://doi.org/10.1016/S1571-0866(07)80034-0, 2007.

Shen, C. C., Li, K. S., Sieh, K., Natawidjaja, D., Cheng, H., Wang, X., Edwards, R. L., Lam, D. D., Hsieh, Y. Te, Fan, T. Y., Meltzner, A. J., Taylor, F. W., Quinn, T. M., Chiang, H. W., and Kilbourne, K. H.: Variation of initial ${ }^{230} \mathrm{Th} /{ }^{232} \mathrm{Th}$ and limits of high precision U-Th dating of shallow-water corals, Geochim. Cosmochim. Ac., 72, 42014223, https://doi.org/10.1016/j.gca.2008.06.011, 2008.

Shinn, E. A., Lidz, B. H., Kindinger, J. L., Hudson, J. H., and Halley, R. B.: Reefs of Florida and the Dry Tortugas: A Guide to the Modern Carbonate Environments of the Florida Keys and the Dry Tortugas, U.S. Geological Survey, St Petersburg, Florida, 1989.

Simo, J. A. T., Guidry, S. A., Iannello, C., Rankey, G., Harris, C. E., Guarin, H., Ruf, A., Hughes, T., Derewetzky, A. N., and Parker, R. S.: Holocene-Pleistocene geology of a transect of an isolated carbonate platform, NW Caicos Platform, British West Indies, Dev. Model. Analog. Isol. Carbonate Platforms-Holocene Pleistocene Carbonates Caicos Platform, Br. West Indies, SEPM Core Work, 22, 111-118, 2008.

Simms, A. R.: Last interglacial sea levels within the Gulf of Mexico and northwestern Caribbean Sea, Earth Syst. Sci. Data, 13, 14191439, https://doi.org/10.5194/essd-13-1419-2021, 2021.

Skrivanek, A., Li, J., and Dutton, A.: Relative sea-level change during the Last Interglacial as recorded in Bahamian fossil reefs, Quaternary Sci. Rev., 200, 160-177, https://doi.org/10.1016/j.quascirev.2018.09.033, 2018.

Speed, R. C. and Cheng, H.: Evolution of marine terraces and sea level in the last interglacial, Cave Hill, Barbados, Bull. Geol. Soc. Am., 116, 219-232, https://doi.org/10.1130/B25167.1, 2004.

Stanley, S. M.: Paleoecology and Diagenesis of Key Largo Limestone, Florida, Bull. Am. Assoc. Pet. Geol., 50,
1927-1947, https://doi.org/10.1306/5D25B6A9-16C1-11D78645000102C1865D, 1966.

Stein, M., Wasserburg, G. J., Aharon, P., Chen, J. H., Zhu, Z. R., Bloom, A. L., and Chappell, J.: TIMS U-series dating and stable isotopes of the last interglacial event in Papua New Guinea, Geochim. Cosmochim. Ac., 57, 2541-2554, https://doi.org/10.1016/0016-7037(93)90416-T, 1993.

Stirling, C. H., Esat, T. M., McCulloch, M. T., and Lambeck, K.: High-precision U-series dating of corals from Western Australia and implications for the timing and duration of the Last Interglacial, Earth Planet. Sc. Lett., 135, 115-130, https://doi.org/10.1016/0012-821X(95)00152-3, 1995.

Stirling, C. H., Esat, T. M., Lambeck, K., and McCulloch, M. T.: Timing and duration of the Last Interglacial: Evidence for a restricted interval of widespread coral reef growth, Earth Planet. Sc. Lett., 160, 745-762, https://doi.org/10.1016/S0012821X(98)00125-3, 1998.

Stirling, C. H., Esat, T. M., Lambeck, K., McCulloch, M. T., Blake, S. G., Lee, D. C., and Halliday, A. N.: Orbital forcing of the marine isotope stage 9 interglacial, Science, 291, 290-293, https://doi.org/10.1126/science.291.5502.290, 2001.

Sweet, W. V., Kopp, R. E., Weaver, C. P., Obeysekera, J., Horton, R. M., Thieler, E. R., and Zervas, C.: Global and regional sea level rise scenarios for the United States, NOAA Technical Report NOS CO-OPS 083, 1-56, 2017.

Szabo, B. J., Ludwig, K. R., Muhs, D. R., and Simmons, K. R.: Thorium-230 ages of corals and duration of the last interglacial sea-level high stand on Oahu, Hawaii, Science, 266, 93-96, https://doi.org/10.1126/science.266.5182.93, 1994.

Taylor, F. W. and Mann, P.: Late Quaternary folding of coral reef terraces, Barbados, Geology, 19, 103-106, https://doi.org/10.1130/ 0091-7613(1991)019<0103:LQFOCR>2.3.CO;2, 1991.

Taylor, S. R. and McLennan, S. M.: The Geochemical Evolution of the Continental Crust, Rev. Geophys., 33, 241-265, https://doi.org/10.1029/95RG00262, 1995.

Thomas, A. L., Henderson, G. M., Deschamps, P., Yokoyama, Y., Mason, A. J., Bard, E., Hamelin, B., Durand, N., and Camoin, G.: Penultimate deglacial sea-level timing from uranium/thorium dating of Tahitian corals, Science, 324, 11861189, https://doi.org/10.1126/science.1168754, 2009.

Thomas, A. L., Fujita, K., Iryu, Y., Bard, E., Cabioch, G., Camoin, G., Cole, J. E., Deschamps, P., Durand, N., Hamelin, B., Heindel, K., Henderson, G. M., Mason, A. J., Matsuda, H., Ménabréaz, L., Omori, A., Quinn, T., Sakai, S., Sato, T., Sugihara, K., Takahashi, Y., Thouveny, N., Tudhope, A. W., Webster, J. M., Westphal, H., and Yokoyama, Y.: Assessing subsidence rates and paleo water-depths for Tahiti reefs using UTh chronology of altered corals, Mar. Geol., 295-298, 86-94, https://doi.org/10.1016/j.margeo.2011.12.006, 2012.

Thompson, S. B. and Creveling, J. R.: A Global Database of Marine Isotope Stage 5a and 5c Marine Terraces and Paleoshoreline Indicators, Earth Syst. Sci. Data Discuss. [preprint], https://doi.org/10.5194/essd-2021-14, in review, 2021.

Thompson, W. G., Spiegelman, M. W., Goldstein, S. L., and Speed, R. C.: An open-system model for U-series age determinations of fossil corals, Earth Planet. Sc. Lett., 210, 365-381, https://doi.org/10.1016/S0012-821X(03)00121-3, 2003.

Thompson, W. G., Allen Curran, H., Wilson, M. A., and White, B.: Sea-level oscillations during the last interglacial high- 
stand recorded by Bahamas corals, Nat. Geosci., 4, 684-687, https://doi.org/10.1038/ngeo1253, 2011.

Tomiak, P. J., Andersen, M. B., Hendy, E. J., Potter, E. K., Johnson, K. G., and Penkman, K. E. H.: The role of skeletal micro-architecture in diagenesis and dating of Acropora palmata, Geochim. Cosmochim. Ac., 183, 153-175, https://doi.org/10.1016/j.gca.2016.03.030, 2016.

Toscano, M. A., Macintyre, I. G., and Lundberg, J.: Last interglacial reef limestones, northeastern St. Croix, US Virgin Islands-evidence of tectonic tilting and subsidence since MIS 5.5, Coral Reefs, 31, 27-38, https://doi.org/10.1007/s00338-0110822-7, 2012.

Trichet, J., Repellin, P., and Oustrière, P.: Stratigraphy and subsidence of the Mururoa atoll (French Polynesia), Mar. Geol., 56, 241-257, https://doi.org/10.1016/0025-3227(84)90016-1, 1984.

Vezina, J., Jones, B., and Ford, D.: Sea-level highstands over the last 500,000 years; evidence from the Ironshore Formation on Grand Cayman, British West Indies, J. Sediment. Res., 69, 317-327, https://doi.org/10.2110/jsr.69.317, 1999.

Villemant, B. and Feuillet, N.: Dating open systems by the ${ }^{238} \mathrm{U}_{-}{ }^{234} \mathrm{U}_{-}{ }^{230} \mathrm{Th}$ method: Application to Quaternary reef terraces, Earth Planet. Sc. Lett., 210, 105-118, https://doi.org/10.1016/S0012-821X(03)00100-6, 2003.

Walter, R. C., Buffler, R. T., Bruggemann, J. H., Guillaume, M. M., Berhe, S. M., Negassi, B., Libsekal, Y., Cheng, H., Edwards, R. L., von Cosel, R., Néraudeau, D., and Gagnon, M.: Early human occupation of the Red Sea coast of Eritrea during the last interglacial, Nature, 405, 65-69, https://doi.org/10.1038/35011048, 2000 .

Wedepohl, K. H.: The Composition of the Continental Crust, Geochim. Cosmochim. Acta, 59, 1217-1232, https://doi.org/10.1016/S0074-6142(09)60137-6, 1995.

Wells, J. W.: Recent Corals of the Marshall Islands, Bikini and nearby Atolls, Part 2, Oceanography (Biologic), Geol. Surv. Prof. Pap. 260-I., 385-486, 1954.
Wessel, P., Smith, W. H. F., Scharroo, R., Luis, J., and Wobbe, F.: Generic mapping tools: Improved version released, Eos, 94, 409410, https://doi.org/10.1002/2013EO450001, 2013.

Whitney, B. B. and Hengesh, J. V.: Geomorphological evidence for late Quaternary tectonic deformation of the Cape Region, coastal west central Australia, Geomorphology, 241, 160-174, https://doi.org/10.1016/j.geomorph.2015.04.010, 2015.

Wilkinson, M. D., Dumontier, M., Aalbersberg, Ij. J., Appleton, G., Axton, M., Baak, A., Blomberg, N., Boiten, J. W., da Silva Santos, L. B., Bourne, P. E., Bouwman, J., Brookes, A. J., Clark, T., Crosas, M., Dillo, I., Dumon, O., Edmunds, S., Evelo, C. T., Finkers, R., Gonzalez-Beltran, A., Gray, A. J. G., Groth, P., Goble, C., Grethe, J. S., Heringa, J., t Hoen, P. A. C., Hooft, R., Kuhn, T., Kok, R., Kok, J., Lusher, S. J., Martone, M. E., Mons, A., Packer, A. L., Persson, B., Rocca-Serra, P., Roos, M., van Schaik, R., Sansone, S. A., Schultes, E., Sengstag, T., Slater, T., Strawn, G., Swertz, M. A., Thompson, M., Van Der Lei, J., Van Mulligen, E., Velterop, J., Waagmeester, A., Wittenburg, P., Wolstencroft, K., Zhao, J., and Mons, B.: Comment: The FAIR Guiding Principles for scientific data management and stewardship, Sci. Data, 3, 1-9, https://doi.org/10.1038/sdata.2016.18, 2016.

Yehudai, M., Lazar, B., Bar, N., Kiro, Y., Agnon, A., Shaked, Y., and Stein, M.: U-Th dating of calcite corals from the Gulf of Aqaba, Geochim. Cosmochim. Ac., 198, 285-298, https://doi.org/10.1016/j.gca.2016.11.005, 2017.

Zazo, C., Goy, J. L., Dabrio, C. J., Soler, V., HillaireMarcel, C., Ghaleb, B., González-Delgado, J. a., Bardají, T., and Cabero, A.: Quaternary marine terraces on Sal Island (Cape Verde archipelago), Quaternary Sci. Rev., 26, 876-893, https://doi.org/10.1016/j.quascirev.2006.12.014, 2007.

Zhu, Z. R., Wyrwoll, K.-H., Collins, L. B., Chen, J. H., Wasserburg, G. J., and Eisenhauer, A.: High-precision U-series dating of Last Interglacial events by mass spectrometry: Houtman Abrolhos Islands, western Australia, Earth Planet. Sc. Lett., 118, 281-293, https://doi.org/10.1016/0012-821X(93)90173-7, 1993. 